Journal of Educational

and Psychological Sciences

Volume (5), Issue (48) : 30 Dec 2021

P: 1 - 19

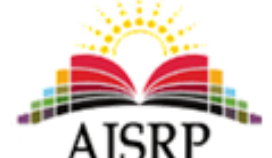

AJSRP

ISSN: 2522-3399

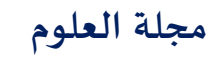

التربوبة والنفسية

المجلد (5)، العدد (48) : 30 ديسمبر 2021 م

ص: 19 - n 19

\title{
The impact of the implementation of the quality system (9001) in controlling administrative, financial and logistical matters in the Ministry of Education
} - An applied study on education in the southern Jordan Valley -

\author{
Rakan Atef Al-Dalain \\ Southern Jordan Valley Education || Ministry of Education || Jordan
}

\begin{abstract}
The aim of the current research is to reveal the impact of the application of the quality system (9001) in controlling administrative, financial and supplies matters in the Ministry of Education, an applied study in the Directorate of Education of the Southern Jordan Valley, and to achieve the objectives of the research, the descriptive analytical method was used, and a questionnaire was developed to collect data from the study sample which consisted of (130) male and female employees working in the Directorate of Education of the Southern Jordan Valley. The research reached a set of results, the most important of which are: the level of apply the quality system came at a high degree with a means of (3.84), and the degree of controlling administrative matters was high with a means of (4.47), and the degree of controlling financial matters was high with a means of (4.26), and the degree of controlling necessary matters was high with a means of (4.09). In addition, there is a statistically significant effect at the significance level $(\alpha \leq 0.05)$ between the application of the quality system (9001) in all its dimensions (administrative responsibility, procurement, document control, and control of quality records) in controlling administrative and financial, and supplies matters in the Directorate of Education of the Southern Jordan Valley. Based on the results reached, the research recommended the need to constantly develop and update the quality system in line with the quality standards (9001) due to its clear impact on improving the performance of the Directorate of Education in the Southern Jordan Valley and its employees, and working to embody the standards and principles of the quality system (9001) in the organizational culture of the Directorate of Education of the Southern Jordan Valley, so that it becomes a major feature of the organizational culture axis and a fundamental pillar for the success of its performance and achievement of its objectives.
\end{abstract}

Keywords: Quality System (9001), administrative matters, financial matters, necessities, Jordanian Ministry of Education.

$$
\begin{aligned}
& \text { أثرتطبيق نظام الجودة (9001) في ضبط الأمور الإدارية والمالية واللوازمية } \\
& \text { في وزارة التربية والتعليم - دراسـة تطبيقية تربية الأغوار الجنوبية - } \\
& \text { راكان عاطف الضهلاعين } \\
& \text { تربية الأغوار الجنوبية || وزارة التربية والتعليم || الأردن }
\end{aligned}
$$

المستخلص: هدف البحث الحالي للكشف عن أثر تطبيق نظام الجودة (9001) في ضبط الأمور الإدارية والمالية واللوازمية في وزارة التربية

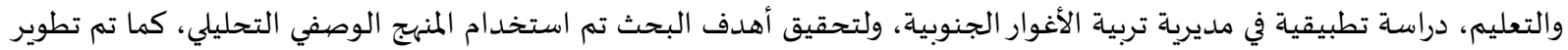

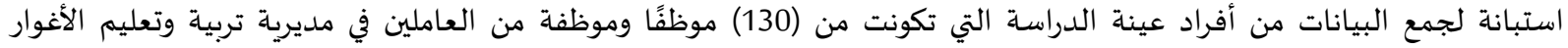

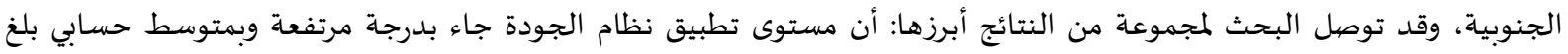


(3.84)، كما أن درجة ضبط الأمور الإدارية جاءت مرتفعة بمتوسط حسابي بلغ (4.47)، ودرجة ضبط الأمور المالية جاءت مرتفعة

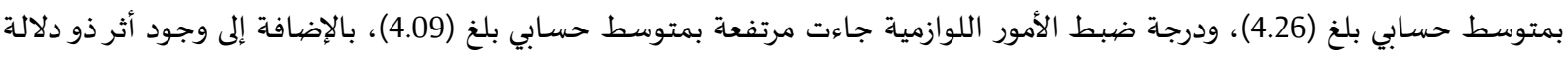

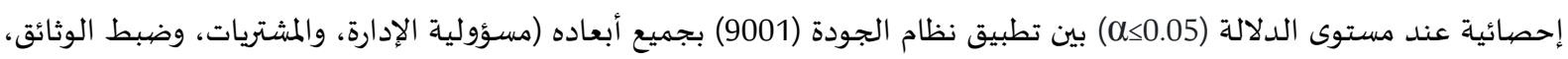

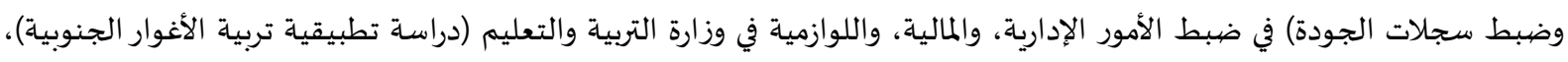

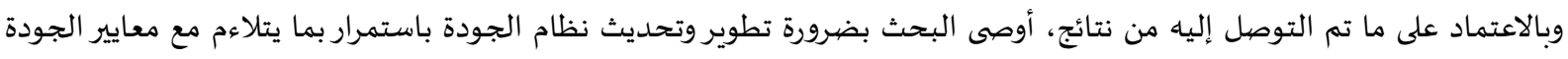

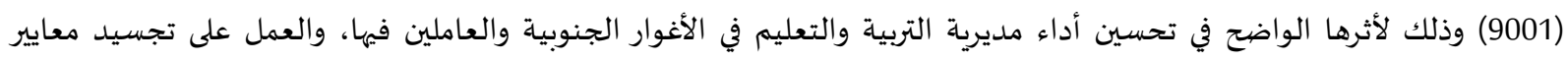

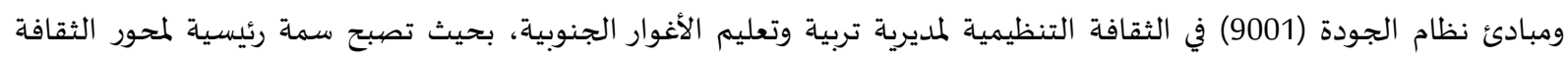
التنظيمية وركيزة أساسية لإنجاح أدائها وتحقيق أهدافها.

الكلمات المفتاحية: نظام الجودة (9001)، الأمور الإدارية، الأمور المالية، الأمور اللوازمية، وزارة التربية والتعليم الأردنية.

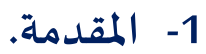

برزت العديد من المصطلحات الإدارية في العصر الحديث التي نالت اهتمام العديد من الباحثين ومن أهم

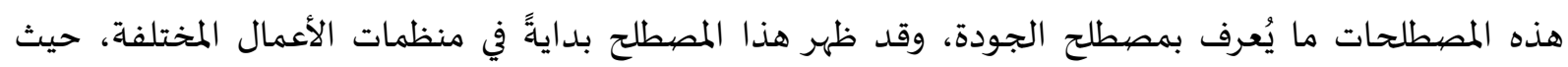

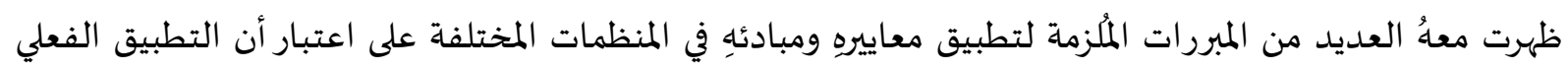
لمفهوم الجودة سيؤثر بشكل ايجابي في تحسين عمليات المنظمة المتنوعة (مدخلات، ومعالجة، ومخرجات

(Besterfield, 2003)

ونظرًا لأهمية وفاعلية معايير الجودة فقد سعت معظم دول العالم لتطبيق هذه المبادئ على كافة الأصعدة

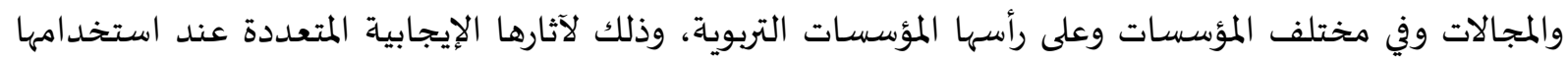

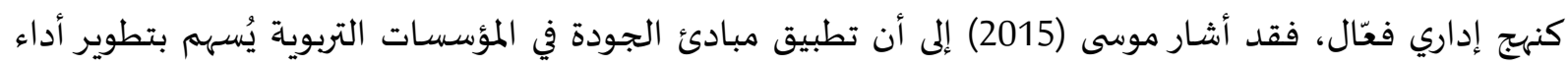

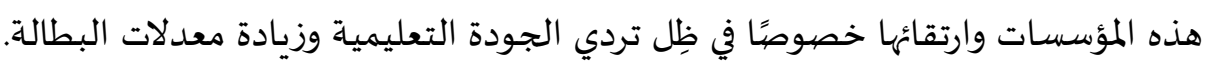

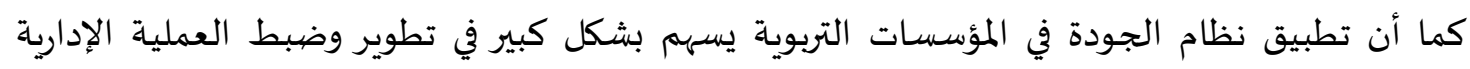

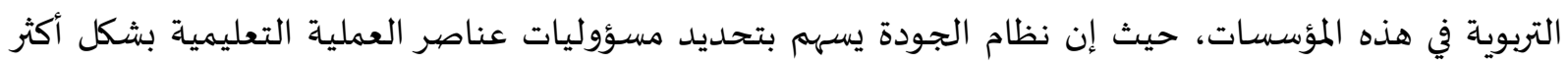

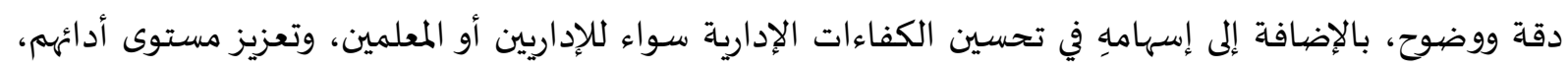

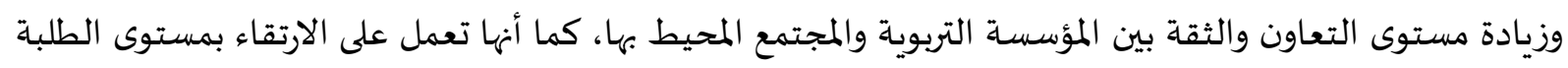

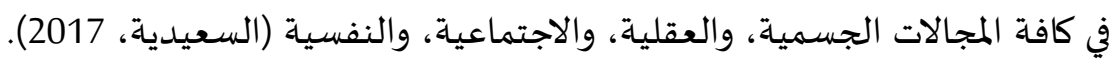

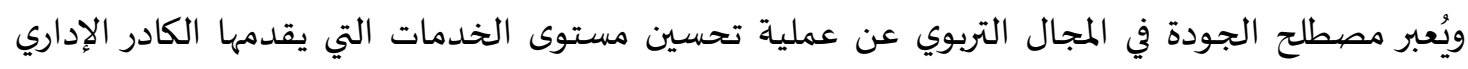

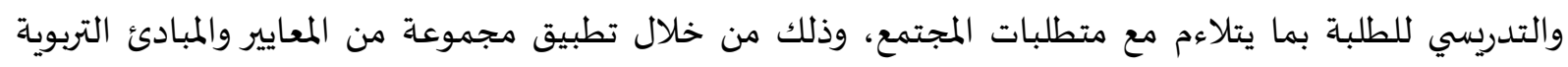

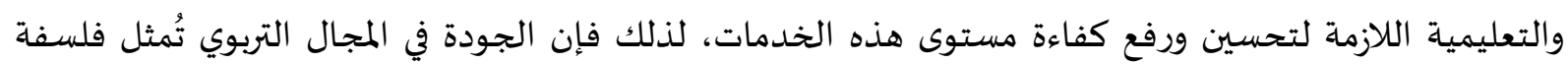

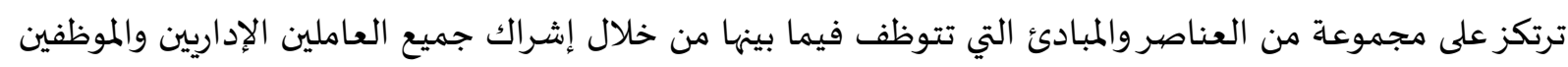
وأفراد المجتمع من أجل خلق ثقافة تنظيمية قادرة على تفعيل معايير الجودة والاستفادة منها بكل كفاءة وفاعلية (بكر، 2018).

وفي الأردن سعت وزارة التربية والتعليم ومنذ بداية القرن الحالي إلى تطبيق الجودة الشاملة في كافة

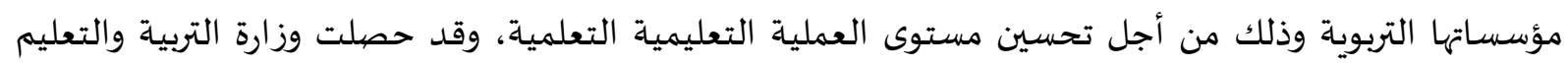

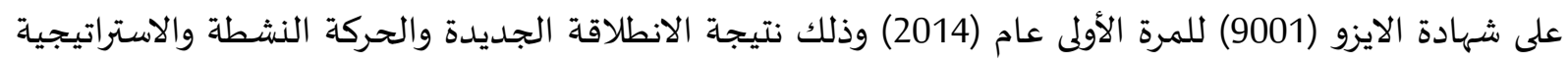
الشـاملة والمتكاملة التي شهدتها وزارة التربية والتعليم من بداية الألفية الحالية (وزارة التربية والتعليم، 2004). 
بناء على ما تم مناقشتهُ، فإن نظام الجودة يعتبر نظام استراتيجي شامل ومتكامل حيث أنهُ يهتم بكافة العناصر الفاعلة في المؤسسة التربوية، فهو يسعى لإيجاد استراتيجية شاملة تغطي كافة جوانب العملية التعليمية

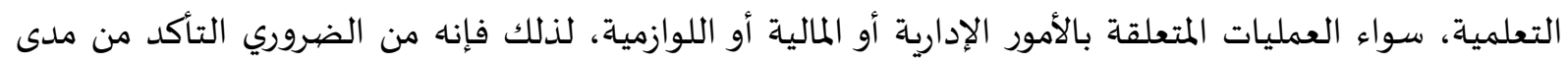

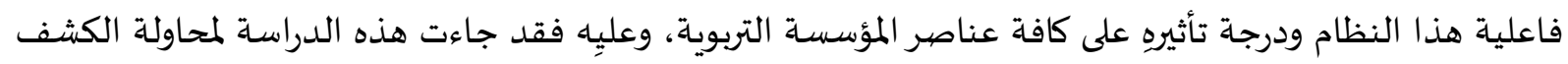

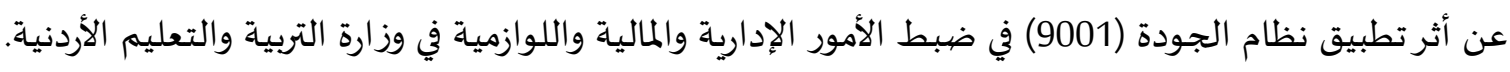

مشكلة البحث

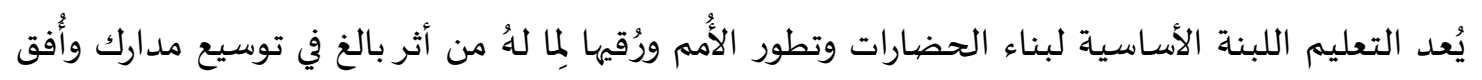

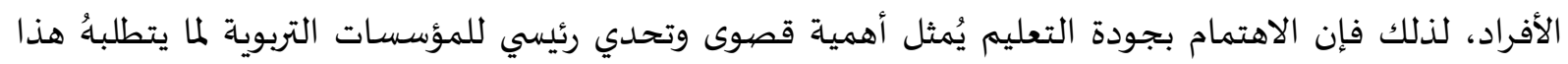

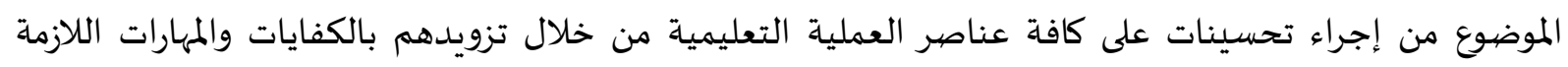

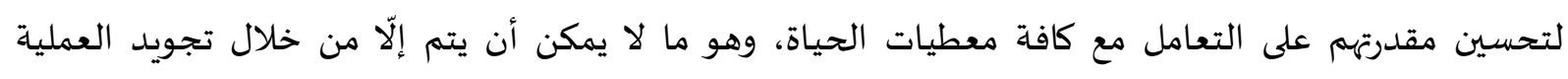
التعليمية (Kim, Kumar \& Kumar, 2011).

وقد أشارت العديد من الدراسات (العدوان والعدوان، 2018؛ السعيدية، 2017؛ الحلو وتعرابت، 2020)

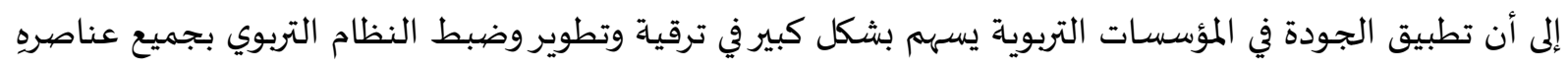

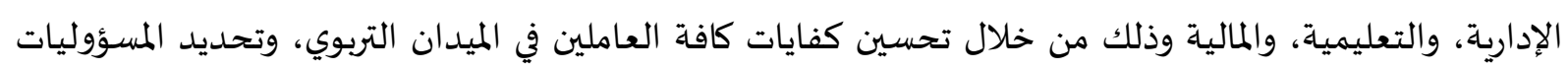

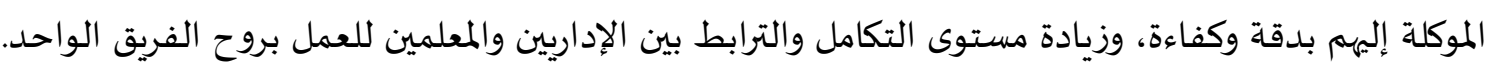

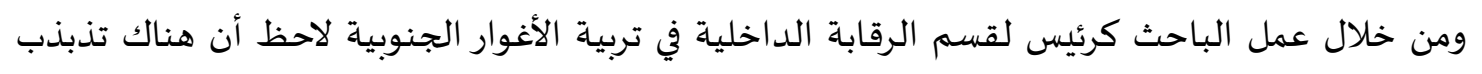

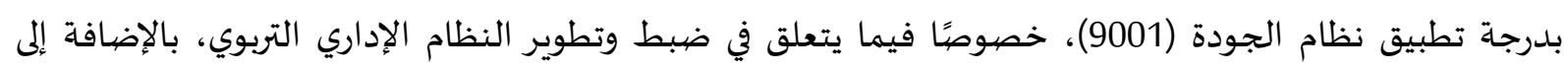
عدم وجود معرفة شاملة لدى بعض الموظفين حول آلية تنفيذ نظام الجودة ودورهِ في ضبط فيط الأمور الإدارية،

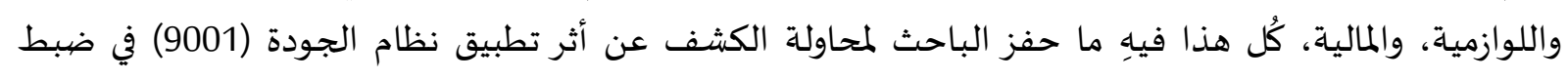

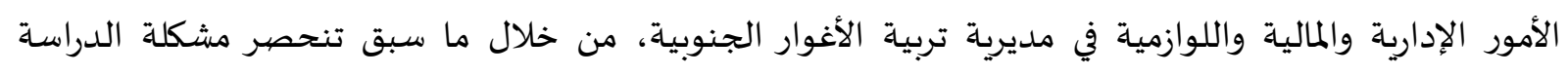
بالإجابة عن السؤال الرئيس التالي: ما أثر تطبيق نظام الجودة (9001) بجميع أبعاده (مسؤولية الإدارة، والمشتريات، وضبط الوتئية الوثائق، وضبط

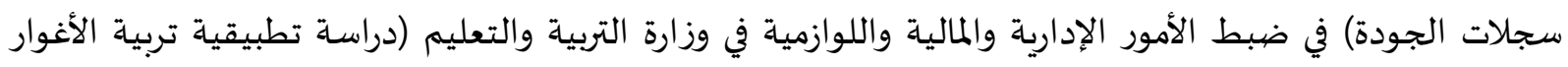

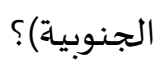

$$
\text { فرضيات البحث }
$$

- الفرضية الأولى: لا يوجد أثر ذو دلالة إحصائية عند مستوى الدلالة (10.05ه) بين تطبيق نظام الجودة (9001)

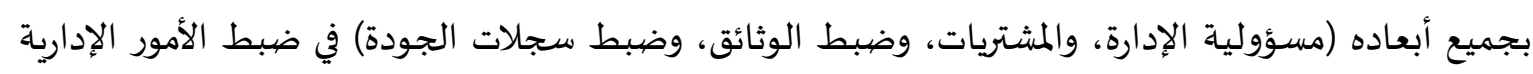
في وزارة التربية والتعليم (دراسة تطبيقية تربية الأغوار الجنوبية).

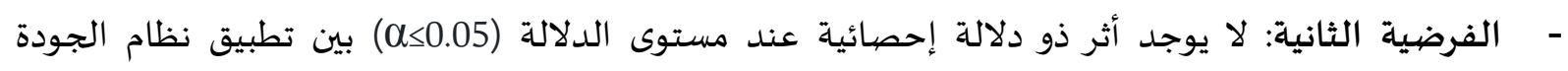

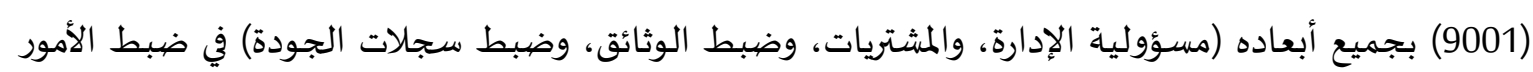
المالية في وزارة التربية والتعليم (دراسة تطبيقية تربية الأغوار الجنوبية). 
- الفرضية الثالثة: لا يوجد أثر ذو دلالة إحصائية عند مستوى الدلالة (10.05ه) بين تطبيق نظام الجودة

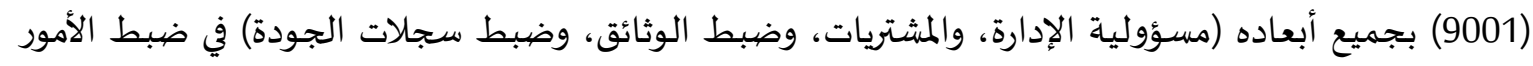
اللوازمية في وزارة التربية والتعليم (دراسة تطبيقية تربية الأغوار الجنوبية).

$$
\text { أهداف البحث }
$$

1- الكشف عن أثر تطبيق نظام الجودة (9001) بجميع أبعاده (مسؤولية الإدارة، والمشتريات، وضبط الإهية الوثائق،

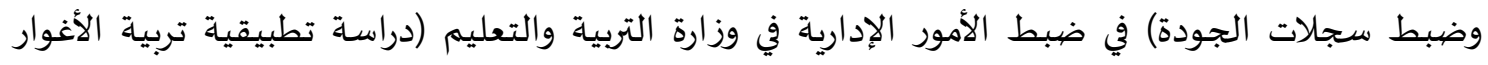

الجنوبية).

2- الكشف عن أثر تطبيق نظام الجودة (9001) بجميع أبعاده (مسؤولية الإدارة، والمشتريات، وضبط الوثائق،

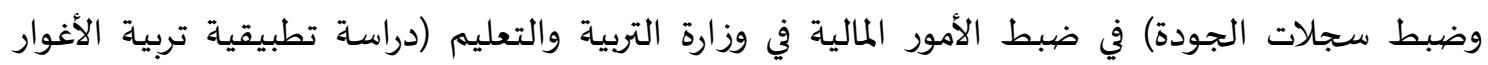

الجنوبية).

3- الكشف عن أثر تطبيق نظام الجودة (9001) بجميع أبعاده (مسؤولية الإدارة، والمشتريات، وضبط الوثائق،

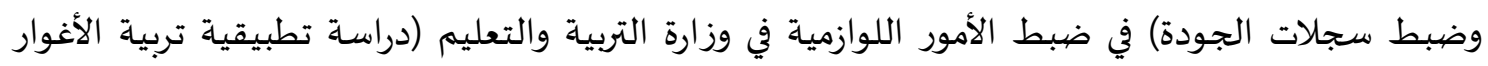

الجنوبية).

أهمية البحث

تنبثق أهمية البحث من خلال: البحث

الأهمية النظرية، وتتمثل في:

1. الكشف عن أثر تطبيق نظام الجودة (9001) في ضبط الأمور الإدارية والمالية واللوازمية في وزارة التربية

والتعليم، مما يُسهم بتعزيز المعرفة النظرية حول مفهوم نظام الجودة (9001) ودورهِ في تحسين أداء

المؤسسات التربوية.

2. ندرة الدراسات التي تناولت أثر تطبيق نظام الجودة (9001) في ضبط الأمور الإدارية والمالية واللوازمية في

$$
\text { المؤسسات التربوية (في حدود علم الباحث). }
$$

3. تناول موضوع ضبط الأمور الإدارية والمالية واللوازمية في وزارة التربية والتعليم، والتي تعتبر من العناصر

الرئيسة في تحقيق أهداف العملية التعليمية التعلمية.

الأهمية التطبيقية، وتتمثل في:

1. إفادها لصناع القرارفي وزارة التربية والتعليم الأردنية في كيفية تطبيق نظام إدارة جودة شامل ومتكامل يُعزز

$$
\text { ويتطور من مستوى أداء المؤسسات التربوية. }
$$

2. إفادها لمديرية التخطيط التربوي وضبط الجودة من خلال إسهامها في ضبط المخرجاء المؤسات التعليمية بما يتلاءم

مع مستقبل العملية التعليمية في المملكة.

3. إفادتها للباحثين والمتخصصين في مجال نظام الجودة في المؤسسات التربوية، حيث تعتبر هذه الدراسة مرجعًا للدراسات المتعلقة بنظام الجودة.

$$
\text { مصطلحات البحث }
$$


نظام الجودة (9001): مجموعة من المعايير والمبادئ والفعاليات والأنشطة التي تسمح للمؤسسات بتوجياء ومراقبة أدائها فيما يختص بالجودة، وذلك من خلال رسم سياسة الجودة، وتحديد أهدافها، والقيام بالتخطيط

لتطبيق الجودة بشكل فعلي، والعمل على تطويرها والارتقاء بها (Cheung \& Yipping, 2008).

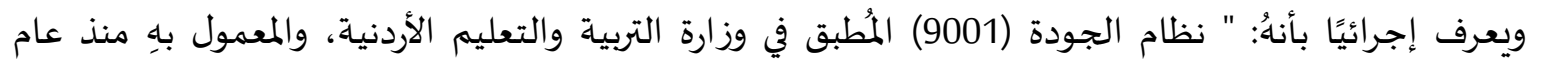

- الأمور الإدارية: تُمثل كافة الأعمال ذات العلاقة بالنظام الإداري في المؤسسة، والمتعلقة بالتخطيط، والتنظيم،

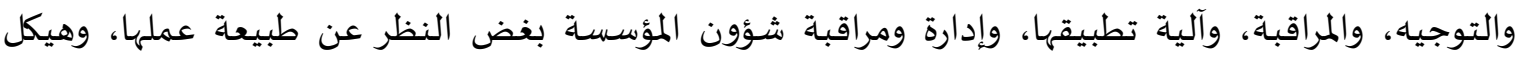

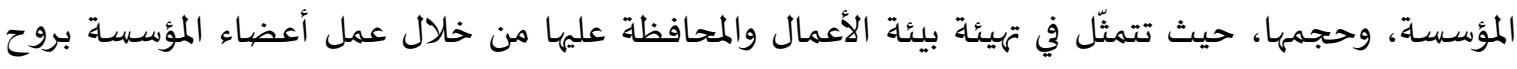

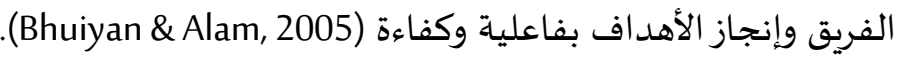
وتعرف إجرائيًا على أهها: " كافة الأنشطة الإدارية التي تنفذها وزاءة التهارة التربية والتعليم الأردنية، كتحديد مسؤوليات

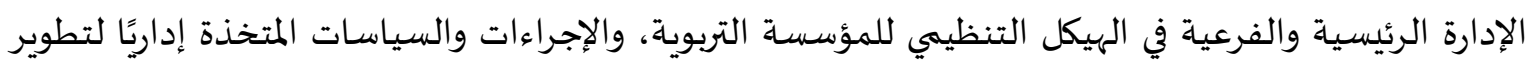
وتحسين أداء المؤسسة التربوية، والخطط الإدارية المرسومة للارتقاء بالعمل الإداري فيها.

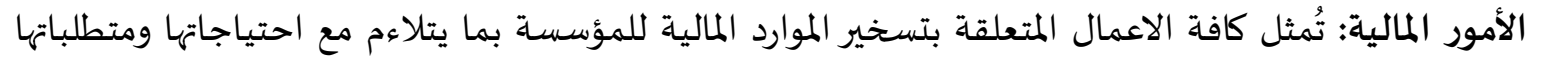
والوضع المالي بكفاءة وفعالية لتحقيق الأهداف التنظيمية (السعود، 2009). وتعرف إجرائيًا بأنها: " كافة المهام ذات الطابع المالي التي تقوم بها وزارة التربية والتعليم الأردنية، سواء فيما يتعلق بصرف رواتب ومكافآت للعاملين في الوزارة أو فيما يتعلق بشراء خدمات المات التهات معينة.

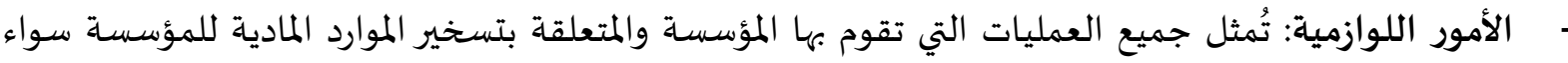

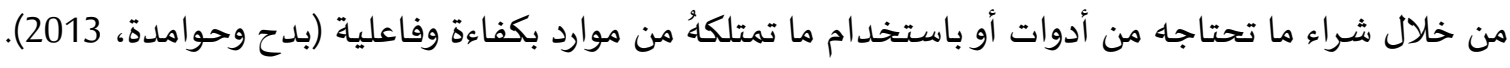

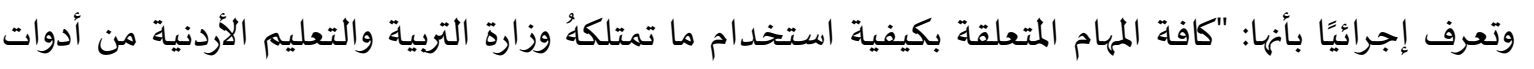
وموارد واستغلالها بأفضل شكل".

حدود البحث

يتحدد البحث بالحدود الآتية:

الحدود الموضوعية: يقتصر البحث على نظام الجودة (9001) والأمور الادارية، والمالية، واللوازمية في مديرية تربية الأغوار الجنوبية. الحدود البشرية: العاملين في مديرية تربية الأغوار الجنوبية والمدارس التابعة لهاء المبا.

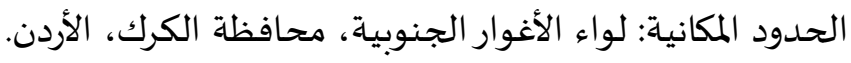
الحدود الزمانية: الفصل الدراسي الثاني للعام الدراسي (2021/2020).

2- 2 - 2 - الدراسـات السـابقة.

يتضمن هذا القسم عرض لمجموعة من الدراسات السابقة ذات العلاقة بموضوع الدراسة الحالية سواء في

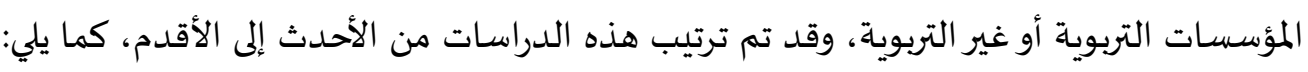

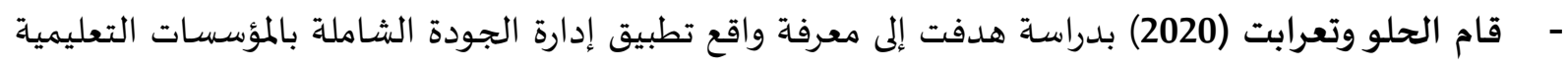

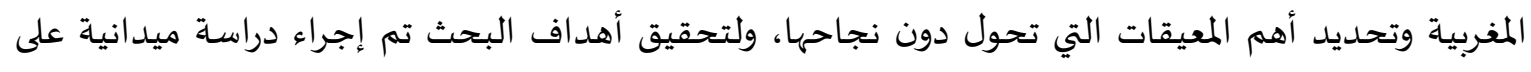

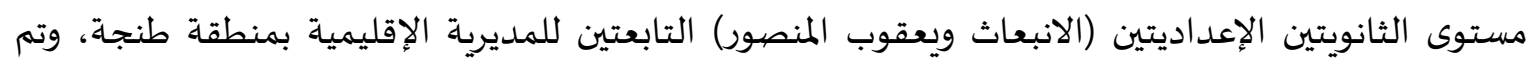


استخدام الاستبانة كأداة رئيسة لجمع البيانات، حيث تم توزيع استمارتين، الأولى موجهة لأطر الإدارة التربوية

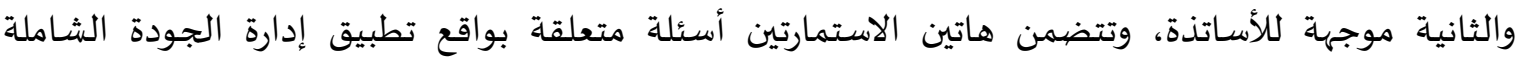

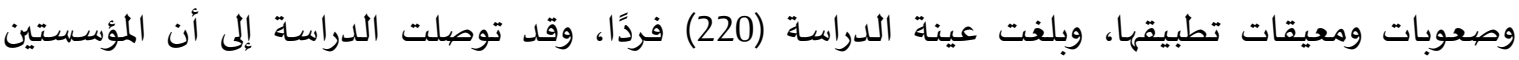

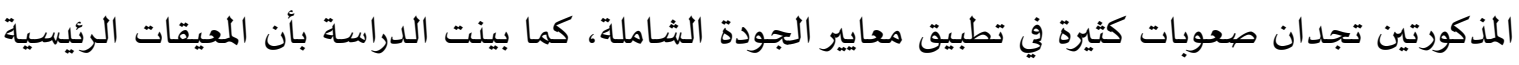

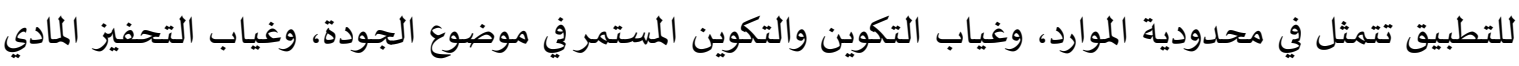
والمعنوي، وضعف التعبئة المجتمعياة. أجرى العدوان والعدوان (2018) دراسة هدفت التعرف إلى درجة تطبيق معايير ضمان الجودة في الجامعات

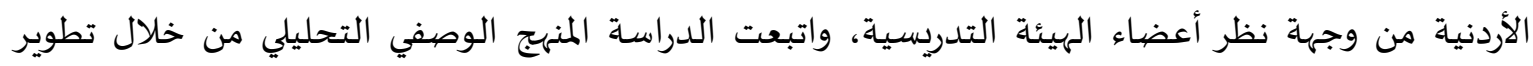

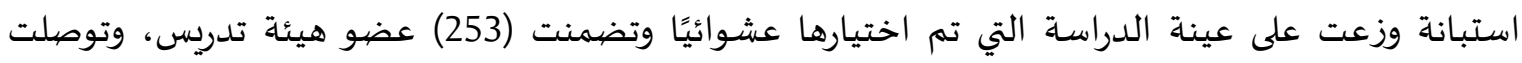

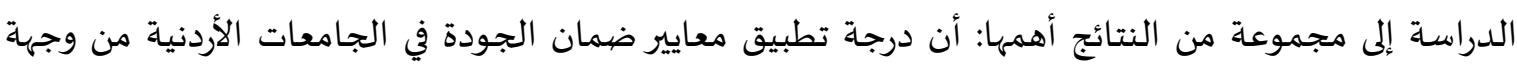

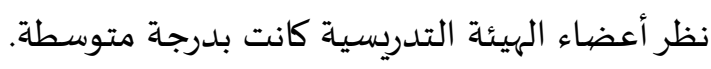
قامت السعيدية (2017) بدراسة هدفت إلى معرفة درجة تطبيق نظام إدارة الجودة في أداء المديريات المطبقة

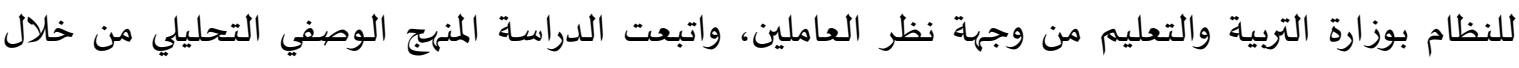

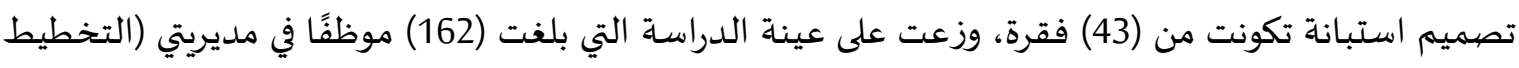

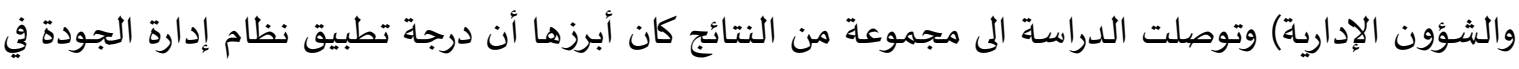

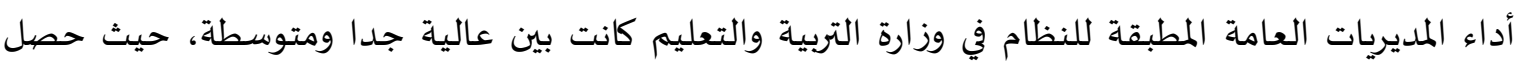

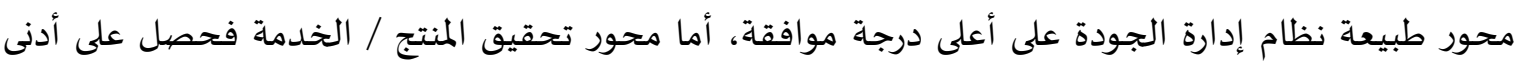

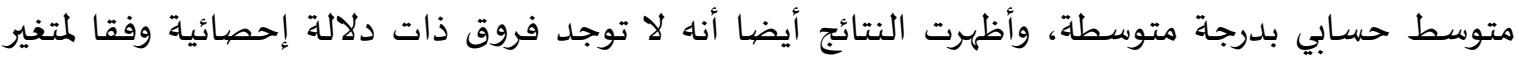

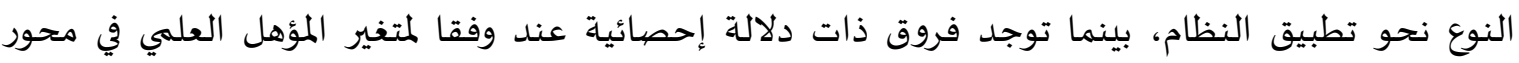
القياس والتحليل والتحسين ولصالح أصحاب المؤهل العلمي العالي. أجرى موسى (2015) دراسة هدفت إلى معرفة أثر تطبيق نظم إدارة الجودة ( ISO 9001/2008) على تحسين

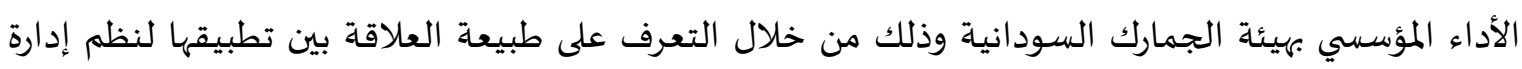

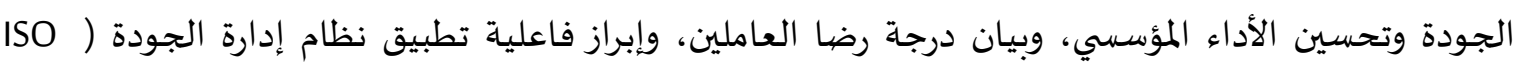

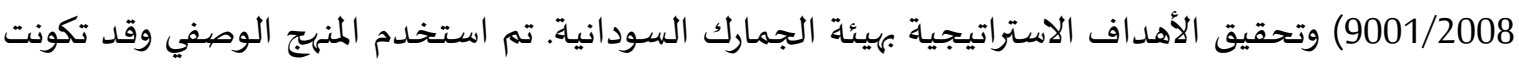

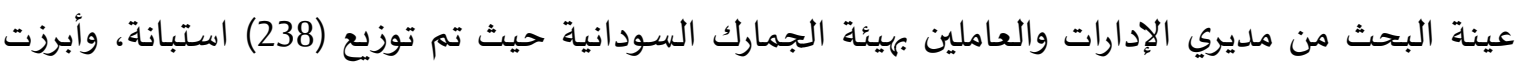

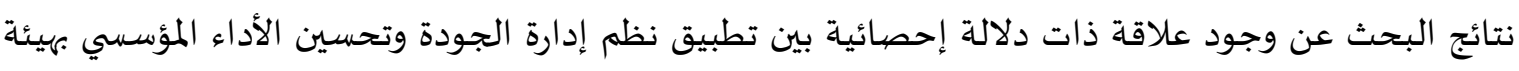

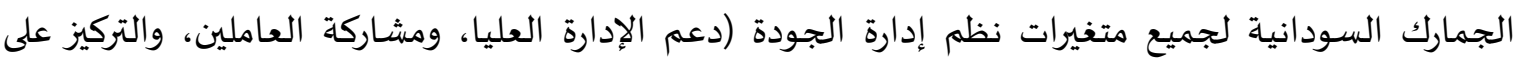

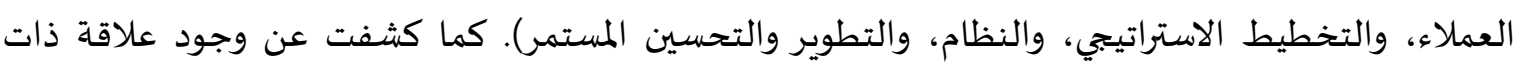

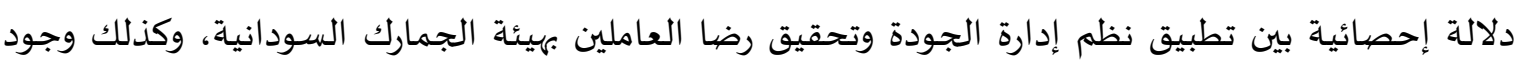
علاقة ذات دلالة إحصائية بين تطبيق نظم إدارة الجودة وتحقيق الأهداف الاستراتيجية بهيئة الجمارك الجمارك السودانية. هدفت دراسة صقر (2013) التعرف إلى درجة تطبيق معايير إدارة الجودة الشاملة في تعليم وتدريب طلبة مركز إعداد رجال الإطفاء في دولة الكويت من وجهة نظر المعلمين والمدربين، ومن أجل تحقيق أهداف الدراسة تم

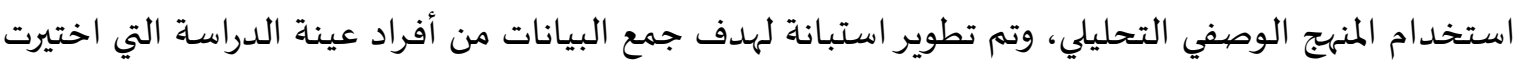

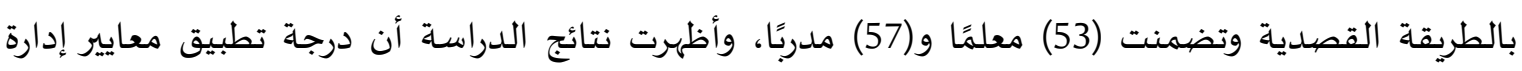


الجودة الشاملة في تعليم وتدريب طلبة مركز إعداد رجال الإطفاء في دولة الكويت من وجهة نظر المعلمين كانت

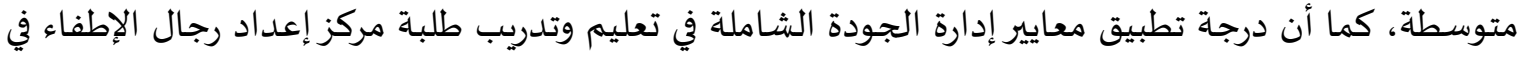

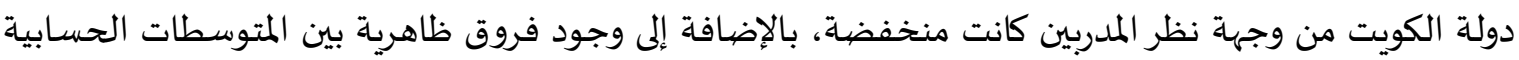

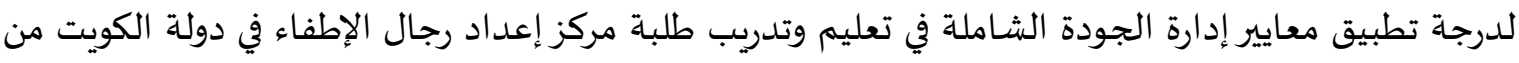

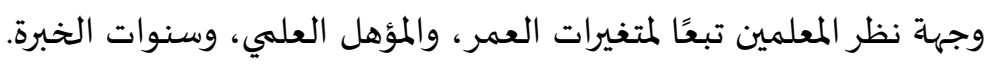
قام بدح وحوامدة (2013) بدراسة هدفت إلى تعرف درجة تطبيق عناصري مواصفات المنظمة الدولية للمقاييس

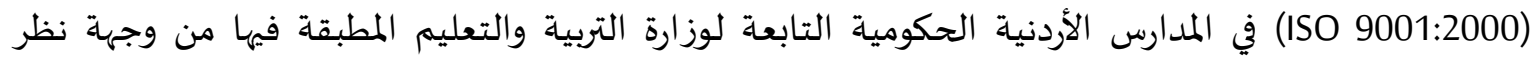

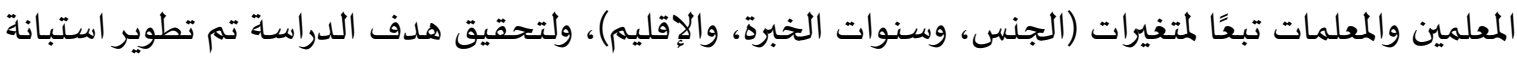

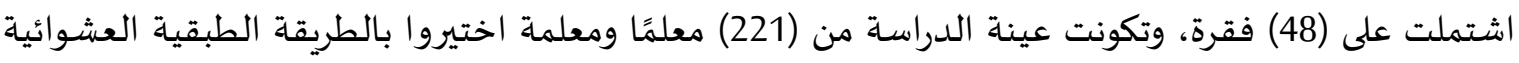

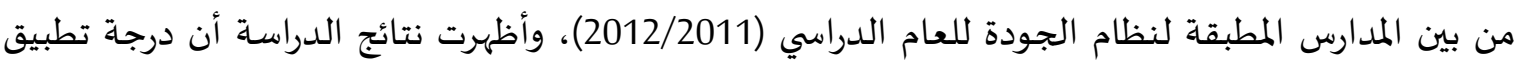

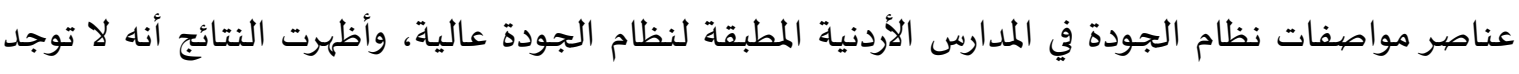

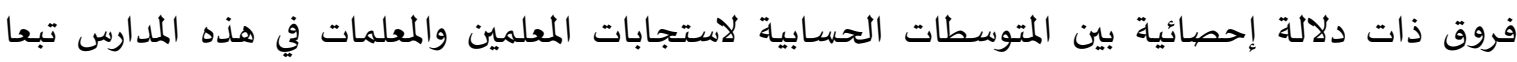
لمتغيرات (الجنس، وسنوات الخبرة، والإقليم). أجرى محافظة وفريحات (2011) دراسة هدفت إلى تعرف درجة ممارسة إدارة الجودة الشاملة في مديريات

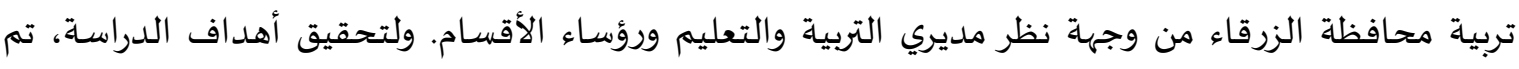
استخدام المنهج الوصفي التحليل من خلال تطوير استبانة اشتملت على (43) فقرة، موزعة على ألى أربعة محاور

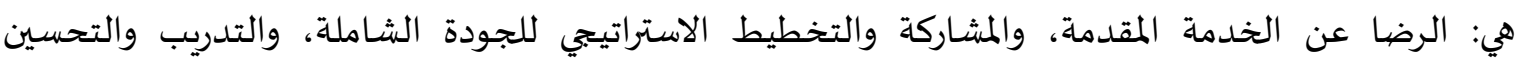

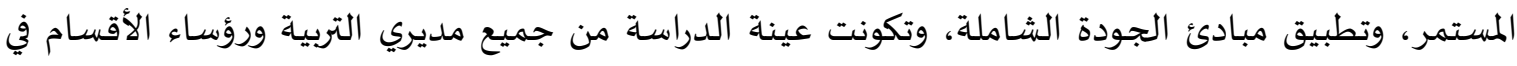

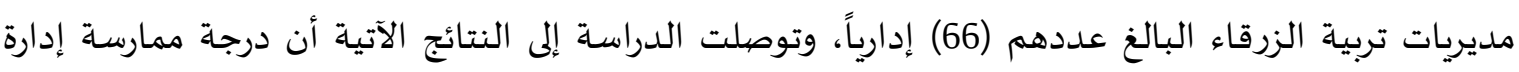

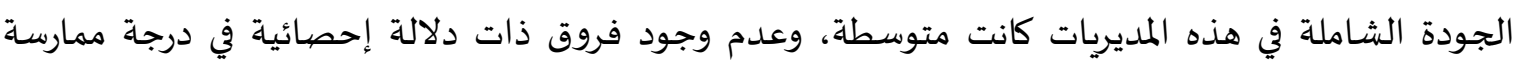

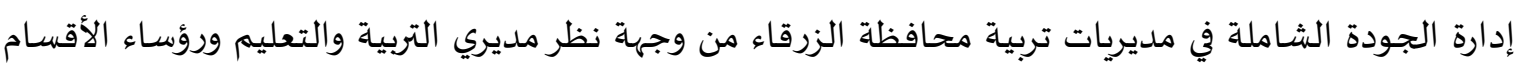

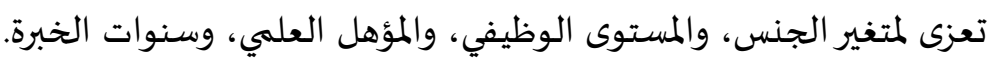

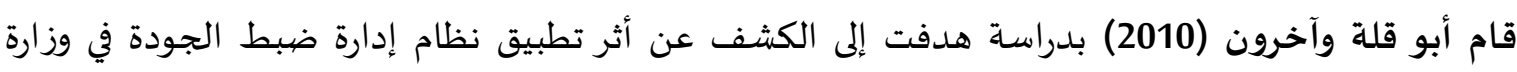

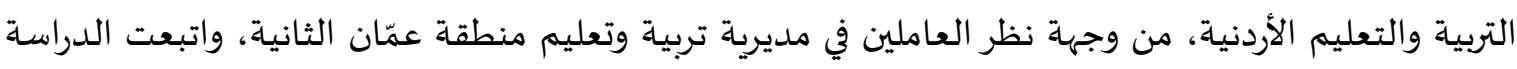

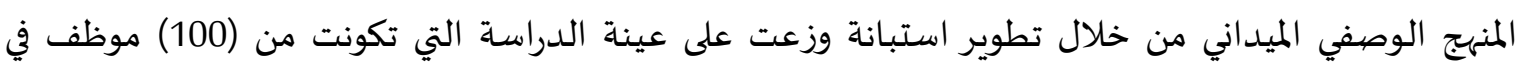

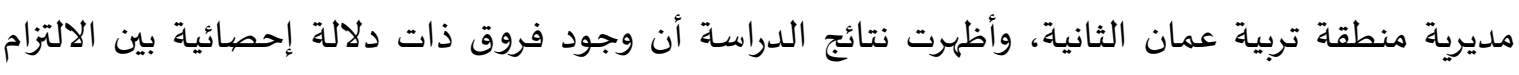

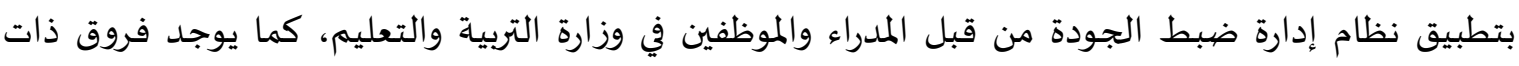

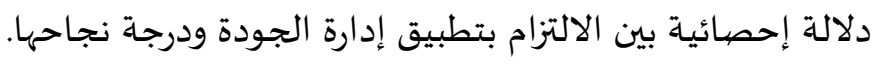

ما يميز هذه الدراسة عن الدراسـات السابقة تناولت الدراسات السابقة الموضوعات ذات بنظام الجودة (9001)، وقد استفادت هذات هذه الدراسة من

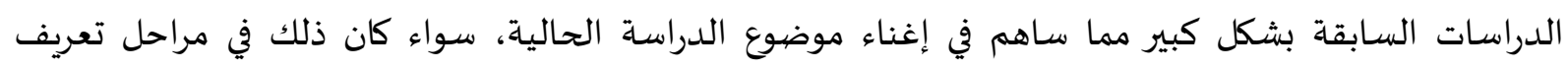

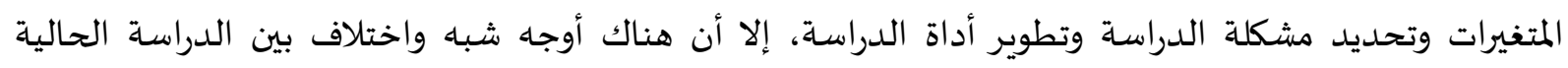
والدراسات السابقة. 
وبالنسبة لأوجاه الشبه فمنها إن هذه الدراسـة مثل جميع الدراسات السابقة تناولت نظام الجودة (9001)

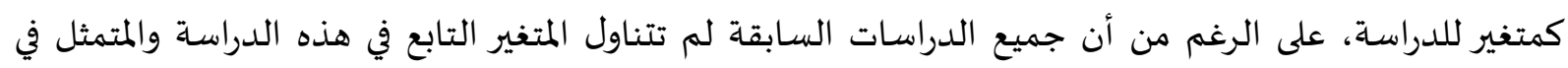
(ضبط الأمور الإدارية، والمالية، واللوازمية)، حيث أن الدراسات السابقة تناولت متغير نظام النام إدارة الجودة وعلاقته

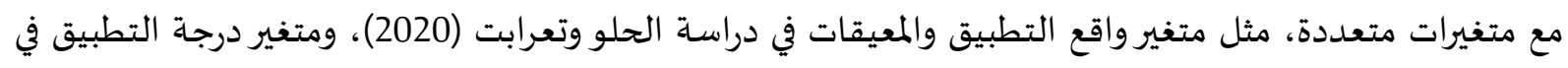

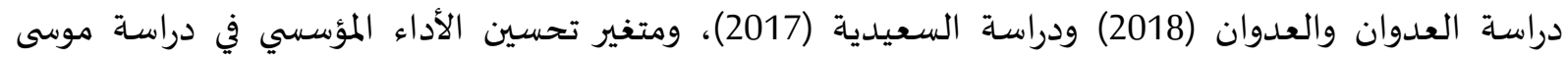
(2015)، أما هذه الدراسة فقد تناولت موضوع نظام إدارة الجودة وأثره في ضبط الأمور الإدارية، والمالية، واللوازمية وهذا ما ميزها عن الدراسات السابقة.

كما تميزت أيضًا هذه الدراسة باختلاف مجتمع الدراسة حيث طُبِقت على في في مديرية تربية وتعليم الأغوار

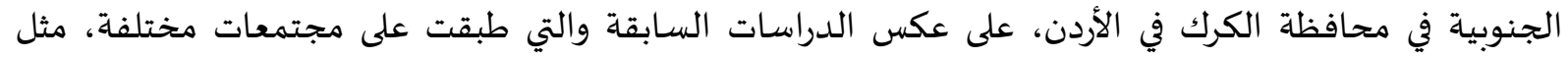

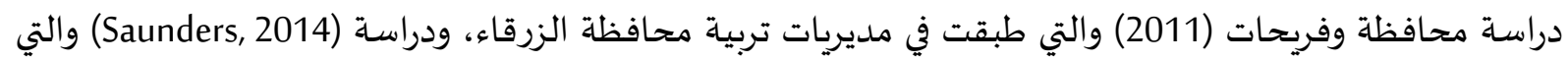

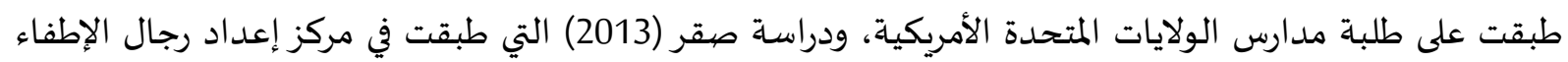
في دولة الكويت.

3- منهجية الدراسة وإجراءاتها.

منهجية الدراسـة:

اعتمدت هذه الدراسة على المنهج الوصفي التحليلي، وذلك لملاءمتهِ لطبيعة الدراسة وأهدافها، بحسب

دراسة العدوان والعدوان (2018) ودراسة الحلو وتعرابت (2020).

مجتمع الدراسـة: - مجن

تكون مجتمع الدراسة من جميع العاملين في مديرية تربية وتعليم لواء الأغوار الجنوبية في محافظة الكرك في الأردن، والبالغ عددهم (150) موظفًا وموظفة، (حسب إحصائيات مديرية شؤون الموظفين في مديرية التربية فئية والتعليم في لواء الأغوار الجنوبية لعام 2021).

عينة الدراسة تم اختيار عينة الدراسة بالطريقة القصدية حيث بلغت عينة الدراسة (150) موظفًا وموظفة، وقد تم

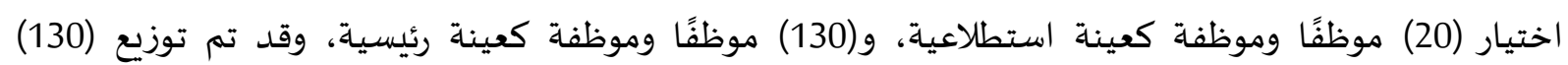

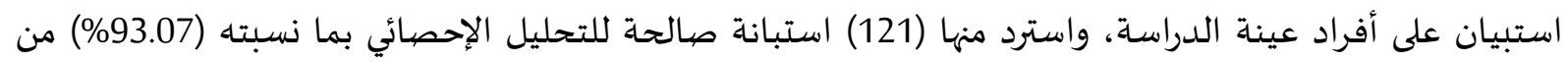

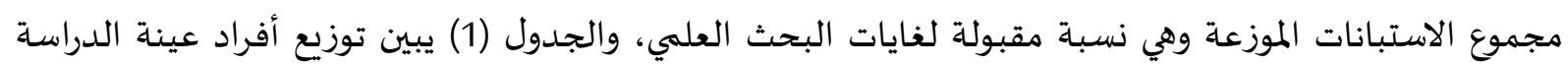
بحسب مُتغيراتها الديموغرافية.

جدول (1): خصائص عينة الدراسة وفقًا لمتغيراتها

\begin{tabular}{|c|c|c|c|}
\hline النسبة & ال العدد & المستوى & المتغير \\
\hline$\% 90.9$ & 110 & ذكر & \multirow{3}{*}{ الجنس } \\
\hline$\% 9.1$ & 11 & أنثى & \\
\hline \%100 & 121 & المجموع & \\
\hline$\% 82.6$ & 100 & بكالوريوس فما دون & المؤهل العلمي \\
\hline
\end{tabular}




\begin{tabular}{|c|c|c|c|}
\hline النسبة & 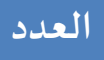 & 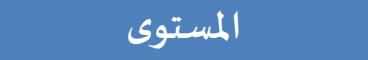 & المتغير \\
\hline$\% 17.4$ & 21 & دراسـات عليا & \\
\hline$\% 100$ & 121 & المجموع & \\
\hline$\% 9.1$ & 11 & أقل من 5 سنوات & \multirow{4}{*}{ الخبرة } \\
\hline$\% 70.2$ & 85 & 5 إلى أقل من 10 سنوات & \\
\hline$\% 20.7$ & 25 & 10 سنوات فأكثر & \\
\hline$\% 100$ & 121 & المجموع & \\
\hline
\end{tabular}

أداة الدراسة

لتحقيق أهداف الدراسة تمّم تطوير استبانة الدراسة من خلال الرجوع إلى الأدب النظري والدراسات

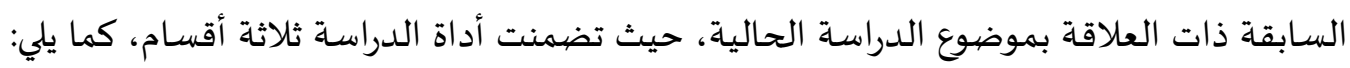
القسم الأول عُني بالمتغيرات الديموغرافية (الجنس، والمؤهل العلمي، والخبرة).

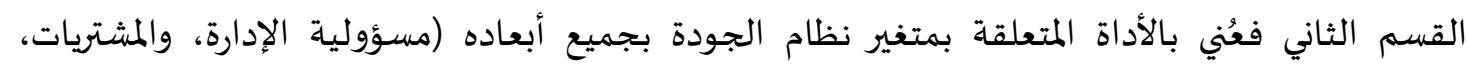

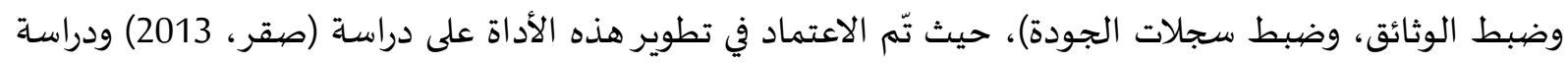

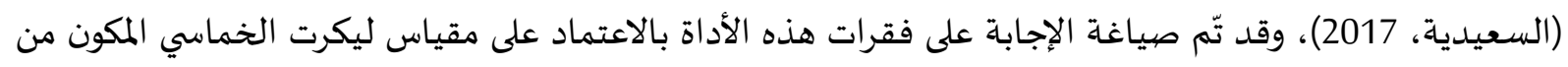

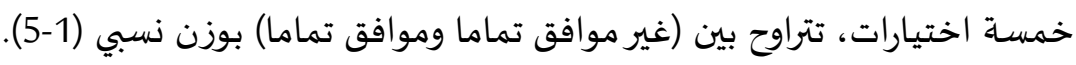

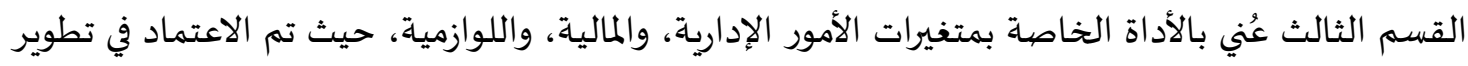

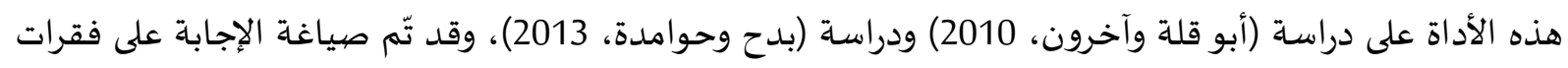

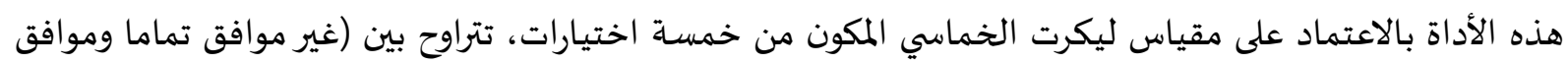
تماما) بوزن نسبي (1-) (1).

صيدق أداة الدراسـة للتحقق من صدق أدوات الدراسة تمّ استخدام صداق المحتوى وصدق البناء الداخلي كما يلي:

صبدق المحتوى:

تم عرض أداة الدراسة بصورتها الأولية على مجموعة من المحكمين ذوي الخبرة والاختصاص من أعضاء

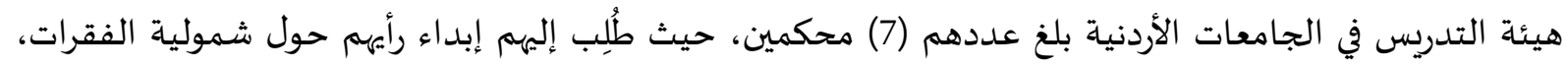

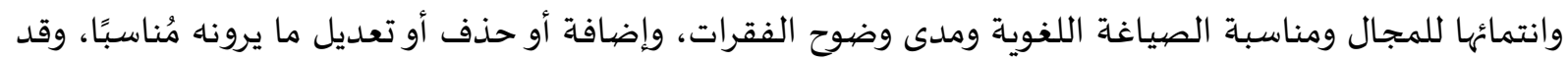
جاءت توصيات المحكمين بإعادة صياغة بعض الفقرات في أداة الدراسة.

صدق البناء الداخلي: تمّ التحقق من صدق أداة الدراسة باستخدام صدل الدق البناء الداخلي، حيث تمّ تطبيق الأداة على عينة

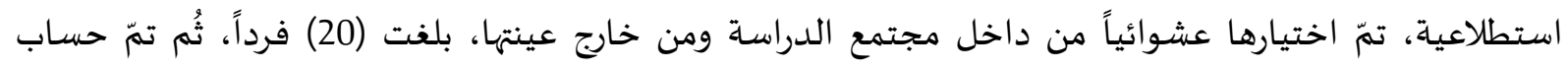

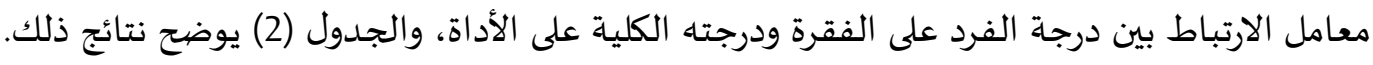


جدول (2): معاملات الارتباط بين درجة الفرد على الفقرة ودرجته الكلية على أداة الدراسة

\begin{tabular}{|c|c|c|c|c|c|}
\hline معامل الارتباط & رقم الذقرة & معامل الآتباط & رقم الفقرة & معامل الإتباط & رقم الفقرة \\
\hline $.399^{*}$ & 25 & $.413^{*}$ & 13 & $.476^{* *}$ & 1 \\
\hline $.462^{*}$ & 26 & $.449^{*}$ & 14 & $.434^{*}$ & 2 \\
\hline $.348^{*}$ & 27 & $.544^{* *}$ & 15 & $.542^{* *}$ & 3 \\
\hline $.568^{* *}$ & 28 & $.602^{* *}$ & 16 & $.465^{*}$ & 4 \\
\hline $.593^{* *}$ & 29 & $.379^{*}$ & 17 & $.604^{* *}$ & 5 \\
\hline $.611^{* *}$ & 30 & $.443^{*}$ & 18 & $.375^{*}$ & 6 \\
\hline $.436^{*}$ & 31 & $.374^{*}$ & 19 & $.456^{*}$ & 7 \\
\hline $.375^{*}$ & 32 & $.434^{*}$ & 20 & $.567^{* *}$ & 8 \\
\hline $.456^{*}$ & 33 & $.542^{* *}$ & 21 & $.462^{*}$ & 9 \\
\hline $.449^{*}$ & 34 & $.465^{*}$ & 22 & $.348^{*}$ & 10 \\
\hline $.544^{* *}$ & 35 & $.568^{* *}$ & 23 & $.568^{* *}$ & 11 \\
\hline & & $.593^{* *}$ & 24 & $.544^{* *}$ & 12 \\
\hline \multicolumn{3}{|c|}{ * تعني دالة عند مستوى (0.01_01) } & \multicolumn{3}{|c|}{ * تعني دالة عند مستوى ( $\leq 0.05)$} \\
\hline
\end{tabular}

يتبين من الجدول (2) بأنه تحقق لأداة الدراسة مؤشرات صدق مناسبة حيث تراوحت معاملات الارتباط

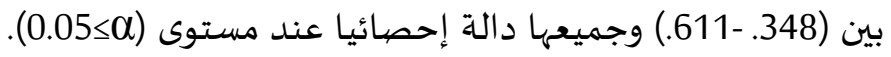

ثبات أداة الدراسـة جرى التأكد من ثبات أداة الدراسة باستخدام معامل كرونباخ ألفا (Cronbach's Alpha) للاتساق الداخلي بصيغته النهائية الكلية، والجدول (3) يبين معامل الثبات كرونباخ ألفا لأبعاد أداة الدراسة.

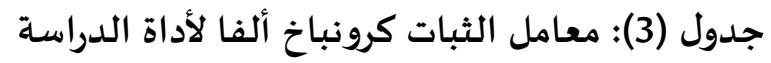

\begin{tabular}{|c|c|c|}
\hline معامل كرونباخ ألفا & 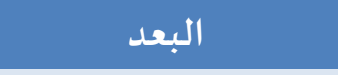 & المتغير \\
\hline 0.81 & مسؤولية الإدارة. & \multirow{4}{*}{ نظام إدارة الجودة } \\
\hline 0.80 & المشتريات. & \\
\hline 0.79 & ضبط الوثائق. & \\
\hline 0.82 & ضبط سجلات الجودة. & \\
\hline 0.82 & الأمور الإدارية & الأمور الإدارية \\
\hline 0.80 & الأمور المالية & الأمور المالية \\
\hline 0.81 & الأمور الللوازمية & الأمور الللوازمية \\
\hline
\end{tabular}

تبين النتائج في الجدول (3) أن معاملات الثبات لأبعاد نظام الجودة تراوحت بين (0.79- 0.82)، في حين أن الن النوريه

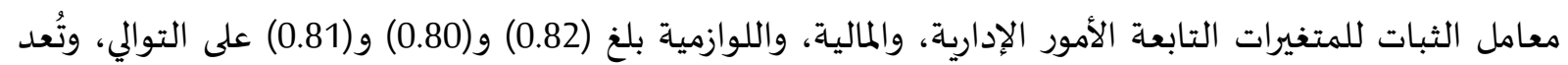
مثل هذه القيم مقبولة لأغراض البحث العلمي. 


\section{طريقة تصحيح أداة الدراسـة:}

تمّ تطبيق الأداة بالطلب من أفراد عينة أن يجيبوا على الأداة بطريقة فردية، وفق تدريج ليكرت الخُماسي،

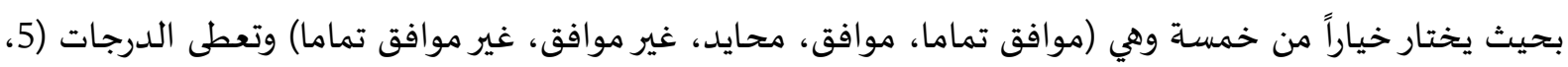

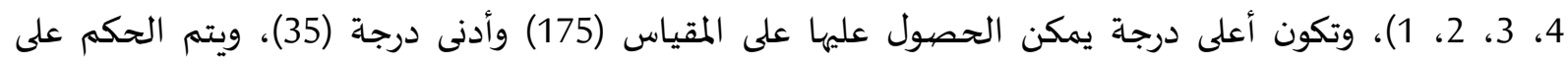

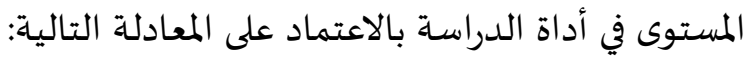

$$
\begin{aligned}
& \text { أعلى قيمة - أقل قيمة / المستويات } \\
& 1.33=3 \div 4=1-5
\end{aligned}
$$

\begin{tabular}{|c|c|}
\hline المستوى بالنسبة للمتوسط الحسابي & المتوسط الحسابي \\
\hline 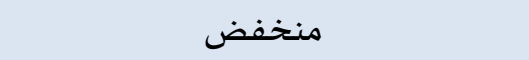 & $1-2.33$ \\
\hline متوسط & $3.67-2.34$ \\
\hline 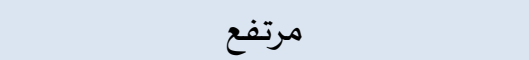 & 3.68فما فوق \\
\hline
\end{tabular}

وبالتالي فإن معيار الحكم كما يلي:

المعالجة الإحصيائية

تم استخدام أساليب الإحصاء الوصفيّ والتحليليّ، وذلك باستخدام الرزمة الإحصائية للعلوم الاجتماعية

(Statistical package For Social Sciences - SPSS 25)

$$
\text { 1. الإحصاء الوصفي: المتوسطات الحسابية والانحرافات المعيارية والتكرارات والنسب المئوية. }
$$

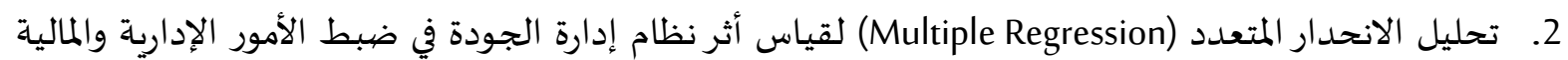

$$
\text { واللوازمية. }
$$

3. اختبار كرونباخ ألفا (Cronbach's Alpha): لاختبار ثبات أداة جمع البيانات المستخدمة في قياس المتغيرات التي

اشتملت عليها الدراسـة.

\section{4- - عرض النتائج ومناقشتها. \\ التحليل الوصفي لفقرات الاستبانة}

للتعرف على آراء أفراد عينة الدراسـة حول متغيرات الدراسـة وتحديد أهمية العبارات الواتة الواردة في الاستبانة،

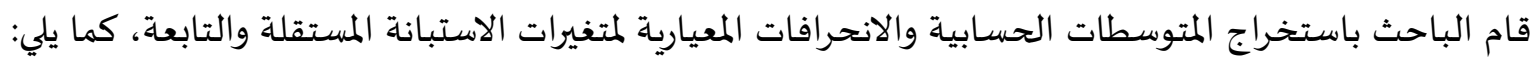

$$
\text { التحليل الوصفي للمتفير المستقل بأبعادهِ: }
$$

\begin{tabular}{|c|c|c|c|c|c|}
\hline الأهمية النسبية & الترتيب & الانحراف المعياري & المتوسط الحسابي & الأبعاد & a \\
\hline مرتفعة & 1 & .747 & 4.19 & المشتريات. & 2 \\
\hline مرتفعة & 2 & .777 & 3.98 & مسؤولية الإدارة. & 1 \\
\hline مرتفعة & 3 & 1.026 & 3.76 & ضبط الوثائق. & 3 \\
\hline
\end{tabular}

للتعرف على آراء أفراد عينة الدراسة المتعلقة بالأهمية النسبية للمتغير المستقل، فقد تم قياسها من خلال

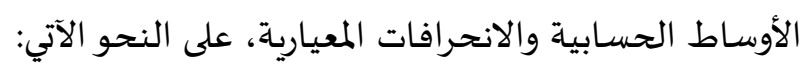

جدول رقم (4): الأوساط الحسابية والانحرافات المعياريّة لآراء عينة الدراسـة حول نظام الجودة بأبعادهِ

أثر تطبيق نظام الجودة (9001) في ضبط الأمور الإدارية و المالية واللوازمية في وزارة التربية والتعليم 


\begin{tabular}{|c|c|c|c|c|c|}
\hline الأهمية النسبية & الترتيب & الاتحراف المعياري & المتوسط الحسابي & الأبعاد & $\hat{\imath}$ \\
\hline متوسطة & 4 & .833 & 3.43 & ضبط سجلات الجودة. & 4 \\
\hline مرتفعة & & .643 & 3.84 & نظام الجودة & 5 \\
\hline
\end{tabular}

يبين الجدول رقم (4) أنّ المتوسطات الحسابية لآراء عينة الدراسة للمتغير المستقل نظام الجودة، جاءت

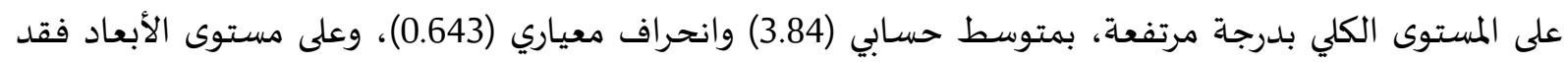

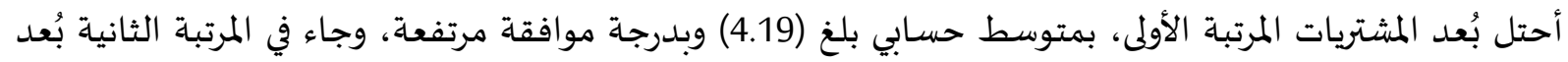

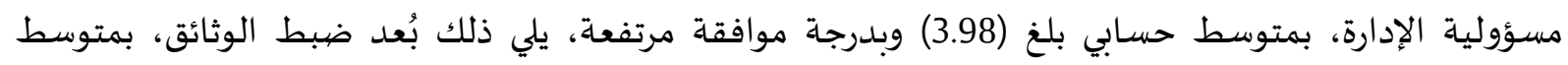

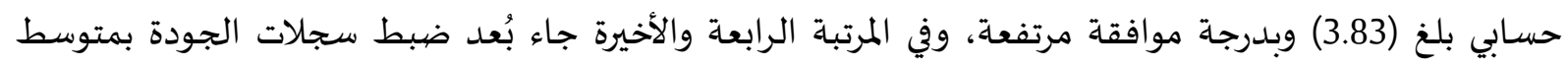
حسابي بلغ (3.43)، وبدرجة موافقة متوسطة.

$$
\text { التحليل الوصفي للمتغيرات التابعة }
$$

للتعرف على آراء أفراد عينة الدراسة المتعلقة بمستوى الأهمية النسبية للمتغيرات التابعة، فقد التهات تم قياسها من خلال الأوساط الحسابية والانحرافات المعيارية، على النحو الآتي:

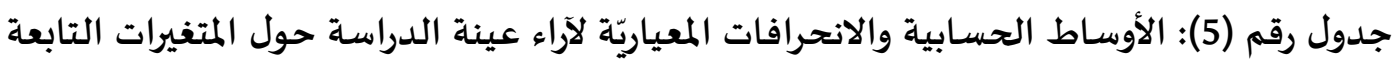

\begin{tabular}{|c|c|c|c|}
\hline الأهمية النسبية & الاتحراف المعياري & المتوسط الحسابي & المتغيرات التابعة \\
\hline مرتفعة & .534 & 4.47 & الأمور الإدارية \\
\hline مرتفعة & .652 & 4.26 & الأمور المالية \\
\hline مرتفعة & .726 & 4.09 & الأمور اللوازمية \\
\hline
\end{tabular}

يبين الجدول رقم (5) أنّ المتوسطات الحسابية لآراء عينة الدراسة للمتغيرات التابعة جاءت كما يلي، بلغ المتوسط الحسابي لمتغير الأمور الإدارية (4.47) بانحراف معياري (0.534)، في حين بلغ المتوسط الحسابة الحسابي لمتغير الأمور

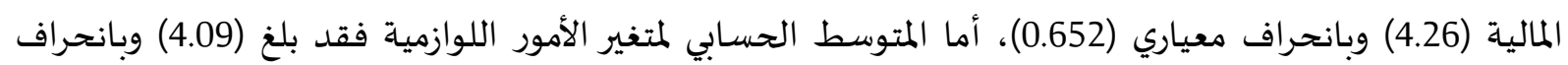
معياري بلغ (0.726). اختبار الفرضيات: قبل البدء في اختبار فرضيات الدراسة تم إجراء بعض الاختبارات، وذلك من أجل ضمان ملائمة البيانات لافتراضات تحليل الانحدار، حيث تم التأكد من عدم وجود ارتباط عالٍ بين المتغيرات المستقلة (Multicollinearity)

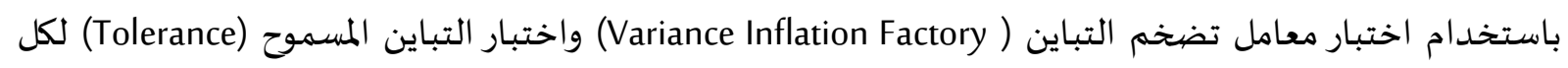

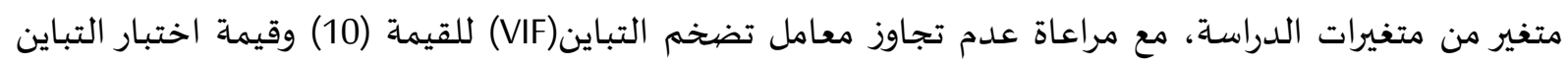

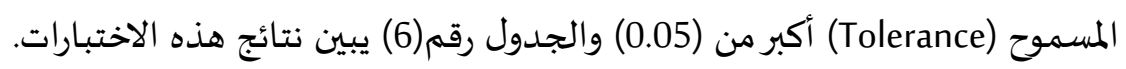

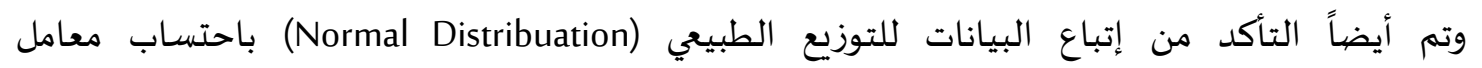

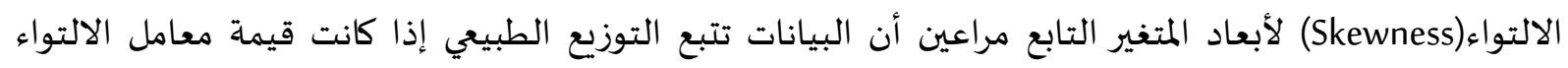
تقترب من(0) والجدول (7) يبين نتائج هذا الاختبار. جدول رقم (6): اختبار معامل تضخم التباين والتباين المسموح للمتغير المستقل

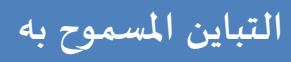
معامل تضخم التباين
أبعاد المتنير المستقل جادول
.438
2.283

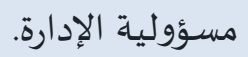




\begin{tabular}{|c|c|c|}
\hline التباين المسموح به & معامل تضخم التباين & أبعاد المتغير المستقل \\
\hline .442 & 2.264 & المشتريات. \\
\hline .340 & 2.942 & ضبط الوثائق. \\
\hline .620 & 1.613 & ضبط سجلات الجودة. \\
\hline
\end{tabular}

نلاحظ أن قيم اختبار معامل تضخم التباين(VIF) لجميع المتغيرات تقل عن 10 وتتراوح بين (1.613-2.942)،

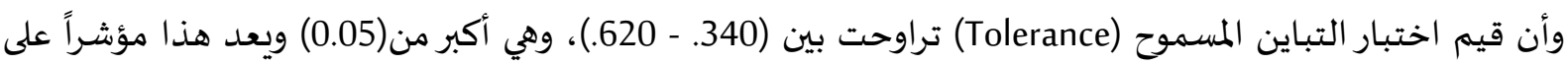
عدم وجود ارتباط عالٍٍ بين المتغيرات المستقلة (Multicollinearity). جدول رقم (7): اختبار معامل الالتواء للمتغيرات التابعة

\begin{tabular}{|c|c|}
\hline معامل الالتواء & أبعاد المتخير التابع \\
\hline-.958 & الأمور الإدارية \\
\hline-.439 & الأمور المالية \\
\hline-.496 & الأمور اللوازمية \\
\hline
\end{tabular}

نلاحظ أن قيم معامل الالتواء كانت القيم تقترب من القيمة (0) يعني أقل من (1)، لذلك يمكن القول بأنه

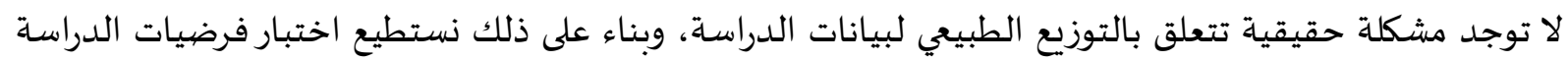
على النحو التالي:

الفرضية الأولى: لا يوجد أثر ذو دلالة إحصائية عند مستوى الدلالة (0.05ه) بين تطبيق نظام الجودة (9001) بجميع أبعاده (مسؤولية الإدارة، والمشتريات، وضبط الوثائق، وضبط سجلاتلات الجودة) في ضبط التهائ الأمور الإدارية في وزارة التربية والتعليم (دراسة تطبيقية تربية الأغوار الجنوبية).

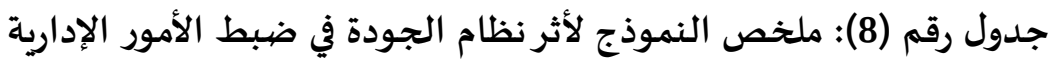
الخطأ المعياري

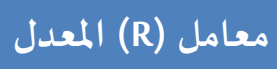

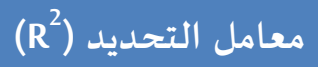

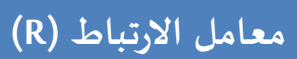
النموذج .37413 .574 .583 .763 1

يوضح الجدول (8) أن قيمة معامل الارتباط للمتغير المستقل (نظام الجودة) والمتغير التابع (الأمور الإدارية)

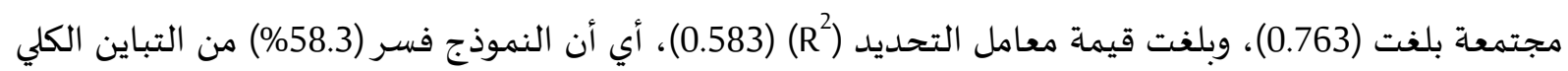
في (الأمور الإدارية) أما الباقي يفسر بعوامل أخرى.

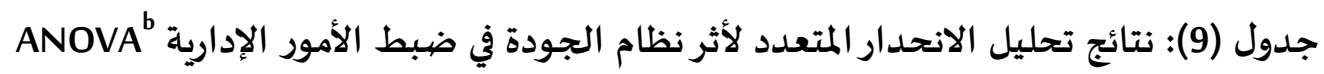

\begin{tabular}{|c|c|c|c|c|c|c|}
\hline مستوى الدلالة & المحسوبة قيمة & متوسط المربعات & درجات الحرية & المربعات متموع & مصيدر البيانان & النموذج \\
\hline \multirow[t]{3}{*}{.000} & 63.360 & 8.869 & 6 & 53.212 & الانحدار & \multirow{3}{*}{1} \\
\hline & & .140 & 272 & 38.073 & الخطأ & \\
\hline & & & 278 & 91.285 & المجموع & \\
\hline
\end{tabular}

يوضح الجدول (9) أن قيمة F بلغت (63.360) وهي أكبر من القيمة الجدولية، وان مستوى الدلالة

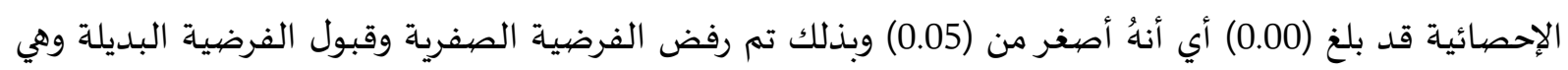

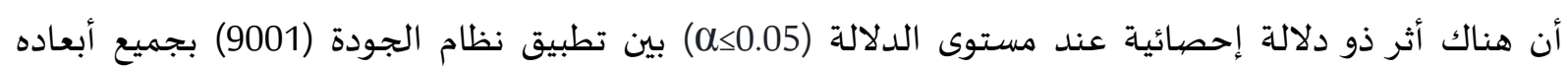


(مسؤولية الإدارة، والمشتريات، وضبط الوثائق، وضبط سجلات الجودة) في ضبط الأمور الإدارية في وزارة التربية والتعليم (دراسـة تطبيقية تربية الأغوار الجنوبية).

جدول (10): نتائج المعاملات لأثر نظام الجودة في ضبط الأبطوبة الأمور الإدارية

\begin{tabular}{|c|c|c|c|c|c|}
\hline \multirow{2}{*}{ مستوى دلالة T } & \multirow{2}{*}{ قيمة T T } & \multirow{2}{*}{ المعاملات المعيارية } & \multicolumn{2}{|c|}{ المعاملات غير المعيارية } & \multirow{2}{*}{ المتغيرات المستقلة } \\
\hline & & & الخطأ المعياري & B & \\
\hline .000 & 14.302 & & .151 & 2.161 & الثابت \\
\hline $.000^{*}$ & 3.786 & .224 & .044 & .165 & مسؤولية الإدارة. \\
\hline $.028^{*}$ & 2.209 & .130 & .045 & .100 & المشتريات. \\
\hline $.045^{*}$ & 2.015 & .135 & .038 & .076 & ضبط الوثائق. \\
\hline $.026^{*}$ & -2.231 & -.099 & .025 & -.056 & ضبط سجلات الجودة. \\
\hline
\end{tabular}

يتضح من النتائج الإحصائية الواردة في الجدول رقم (19)، أن قيم الدلالة المعنوية بلغت (0.00، 0.028،

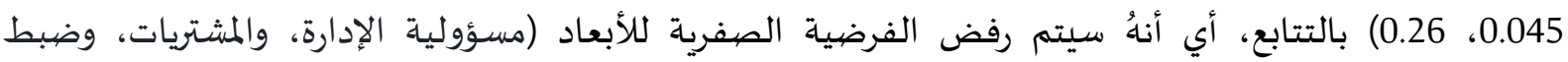
الوثائق، وضبط سجلات الجودة) بمعنى وجود أثر لهذه المتغيرات في ضبط النئ الأمور الإدارية.

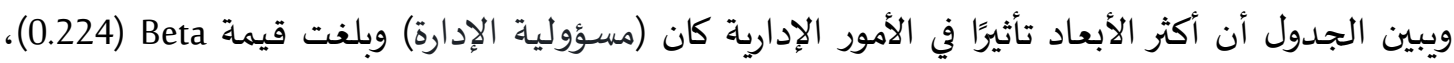

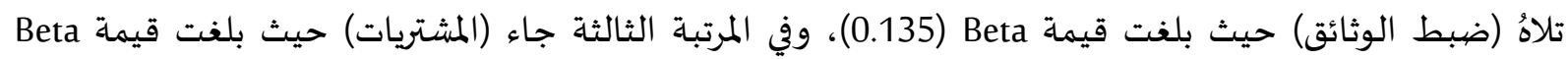
(0.130)، وكان أقل الأبعاد تأثيرًا (ضبط سجاتلات الجودة) حيث بلغت قيمة Beta (0.099).

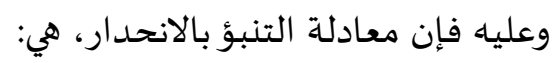
$Y=\alpha+b_{1} x_{1}+b_{2} x_{2}+b_{3} x_{3}+b_{4} x_{4}$.

الفرضية الثانية: لا يوجد أثر ذو دلالة إحصائية عند مستوى الدلالة (ب0.05ه) بين تطبيق نظام الجودة

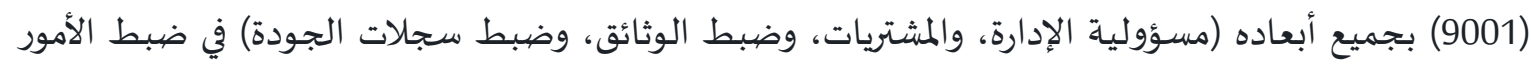

المالية في وزارة التربية والتعليم (دراسة تطبيقية تربية الأغوار الجنوبية). جدول رقم (11): ملخص النموذج لأثر نظام الجودة في ضبط الاعوار اجنوبية الأمور المالية

\begin{tabular}{|c|c|c|}
\hline الخطأ المعياري & معامل (R) المعدل & معامل التحديد (R²) \\
\hline .37565 & .507 & .517 \\
\hline
\end{tabular}

يوضح الجدول (11) أن قيمة معامل الارتباط للمتغير المستقل (نظام الجودة) والمتغير التابع (الأمور المالية)

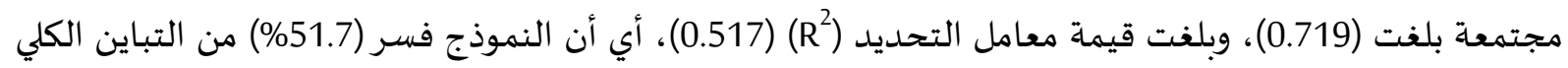

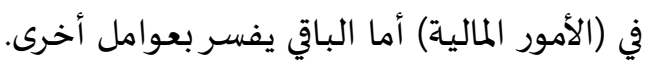

جلدول (12): نتائج تحليل الانحدار المتعدد لأثر نظام الجودة في ضبط الأمور المالية ألماية

\begin{tabular}{|c|c|c|c|c|c|c|}
\hline مستوى الدلالة & المحسوبة F قيمة & متوسط & درجات الحرية & المربعات & مصيدر البيانا: & النموذج \\
\hline \multirow[t]{3}{*}{.000} & 48.583 & 6.856 & 6 & 41.135 & الانحدار & \multirow{3}{*}{1} \\
\hline & & .141 & 272 & 38.383 & الخطأ & \\
\hline & & & 278 & 79.518 & المجموع & \\
\hline
\end{tabular}

يوضح الجدول (12) أن قيمة F بلغت (0.583) وهي أكبر من القيمة الجدولية، وان مستوى الدلالة الإحصائية قد بلغ (0.00) أي أنهُ أصغر من (0.05) وبذلك تم رفض الفرضية الصفرية وقبول الفرضية البديلة وهي 


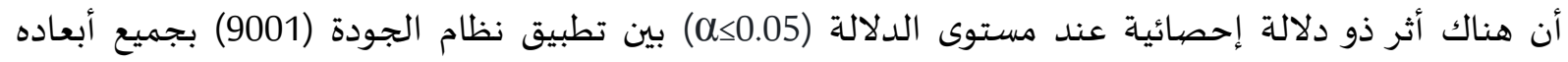

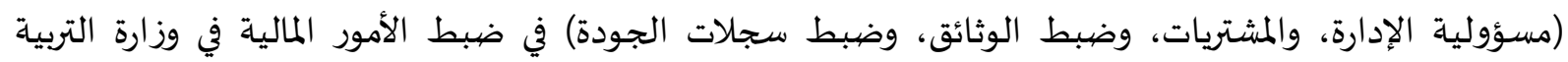
والتعليم (دراسـة تطبيقية تربية الأغوار الجنوبية).

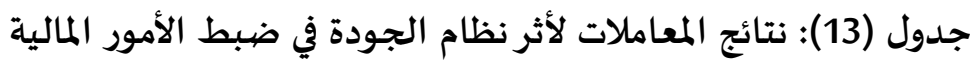

\begin{tabular}{|c|c|c|c|c|c|}
\hline \multirow{2}{*}{ مستوى دلالة T } & \multirow{2}{*}{ ق قيمة T T } & \multirow{2}{*}{ المعاملات المعيارية } & \multicolumn{2}{|c|}{ المعاملات غير المعيارية } & \multirow{2}{*}{ المتغيرات المستقلة } \\
\hline & & & الخطأ المعياري & B & \\
\hline .000 & 15.321 & & .152 & 2.324 & الثابت \\
\hline $.001^{*}$ & 3.252 & .207 & .044 & .142 & مسؤولية الإدارة. \\
\hline $.000^{*}$ & 5.051 & .320 & .045 & .229 & المشتريات. \\
\hline $.019^{*}$ & -2.365 & -.113 & .025 & -.059 & ضبط الوثائق. \\
\hline $.000^{*}$ & 5.779 & .384 & .041 & .237 & ضبط سجلات الجودة. \\
\hline
\end{tabular}

يتضح من النتائج الإحصائية الواردة في الجدول رقم (13)، أن قيم الدلالة المعنوية بلفت (0.001، 0.000،

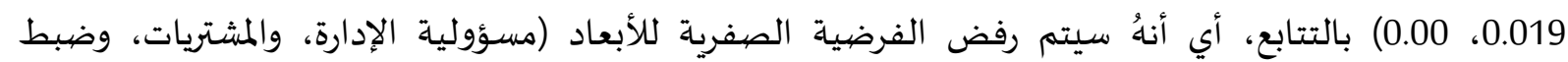
الوثائق، وضبط سجلات الجودة) بمعنى وجود أثر لهذه المتغيرات في الأمور المالية.

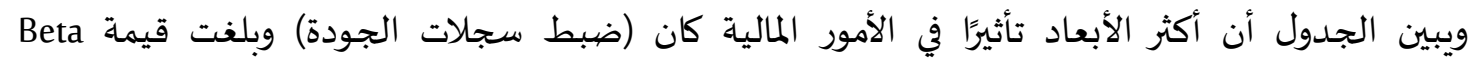

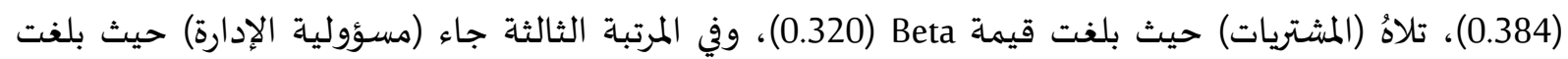

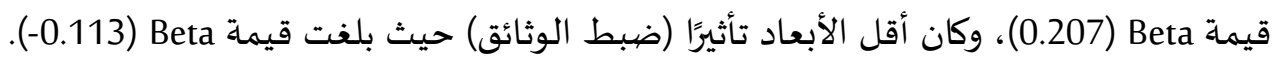
وعليه فإن معادلة التنبؤ بالانحدار، هي: الانياد تاتيرًان $Y=\alpha+b_{1} x_{1}+b_{2} x_{2}+b_{3} x_{3}+b_{4} x_{4}$

الفرضية الثالثة: لا يوجد أثر ذو دلالة إحصائية عند مستوى الدلالة (10.05ه) بين تطبيق نظام الجودة

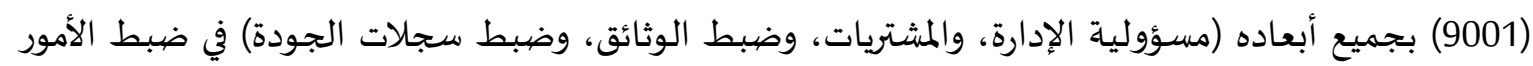
اللوازمية في وزارة التربية والتعليم (دراسة تطبيقية تربية الأغوار الجنوبية).

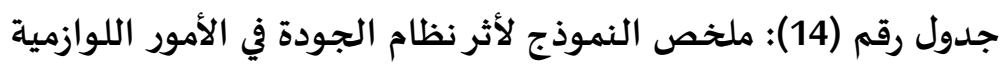

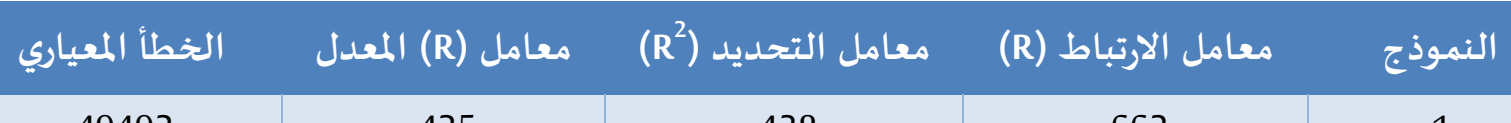
.49492 .425 .438 .662

يوضح الجدول (23) أن قيمة معامل الارتباط للمتغير المستقل (نظام الجودة) والمتغير التابع (الأمور

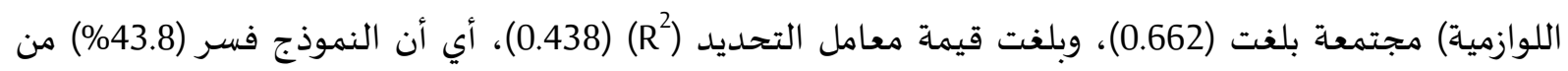

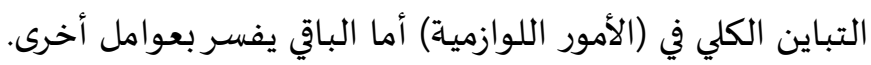

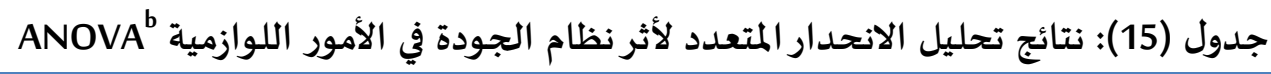

\begin{tabular}{|c|c|c|c|c|c|c|}
\hline مستوى الدلالة المعنوية لـ FSig & المحسوبة F قيمة & متوسط المربعات & درجات الحرية & المربعات متموع & مصيدر البيانات & النموذج \\
\hline \multirow[t]{3}{*}{.000} & 35.312 & 8.650 & 6 & 51.898 & الانحدار & \multirow{3}{*}{1} \\
\hline & & .245 & 272 & 66.626 & الخطأ & \\
\hline & & & 278 & 118.524 & المجموع & \\
\hline
\end{tabular}


يوضح الجدول (15) أن قيمة F بلغت (35.312) وهي أكبر من القيمة الجدولية، وان مستوى الدلالة

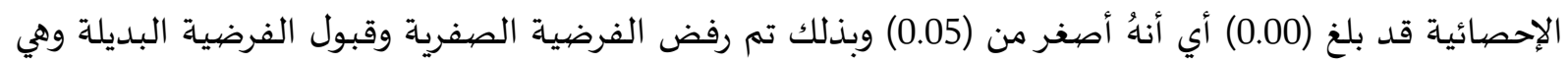
أن هناك أثر ذو دلالة إحصائية عند مستوى الدلالة (Us0.05) بين تطبيق نظام الجودة (0001) بجميع أبعاده (مسؤولية الإدارة، والمشتريات، وضبط الوثائق، وضبط سجاتلات الحبات الجودة) في ضبط الأمور اللوازمية في وزارة التربية

والتعليم (دراسـة تطبيقية تربية الأغوار الجنوبية).

جدول (16): نتائج المعاملات لأثر نظام الجودة في الأبهاء الأمور اللوازمية

\begin{tabular}{|c|c|c|c|c|c|}
\hline \multirow{2}{*}{ مستوى دلالة T } & \multirow{2}{*}{ قيمة T T } & \multirow{2}{*}{ المعاملات المعيارية } & \multicolumn{2}{|c|}{ المعاملات غير المعيارية } & \multirow{2}{*}{ المتفيرات المستقلة } \\
\hline & & & الخطأ المعياري & B & \\
\hline .000 & 11.180 & & .200 & 2.234 & الثابت \\
\hline $.000 *$ & 3.552 & .244 & .058 & .205 & مسؤولية الإدارة. \\
\hline $.037^{*}$ & 2.099 & .164 & .050 & .104 & المشتريات. \\
\hline $.017^{*}$ & -2.405 & -.139 & .045 & -.109 & ضبط الوثائق. \\
\hline $.000^{*}$ & 4.547 & .326 & .054 & .246 & ضبط سجلات الجودة. \\
\hline
\end{tabular}

يتضح من النتائج الإحصائية الواردة في الجدول رقم (16)، أن قيم الدلالة المعنوية بلغت (0.000، 0.037،

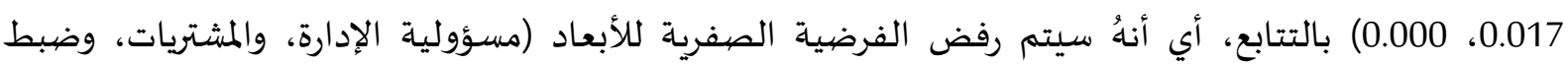
الوثائق، وضبط سجلات الجودة) بمعنى وجود أثر لهذه المتغيرات في الأمور اللوازمية.

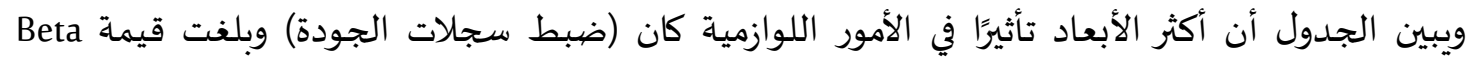

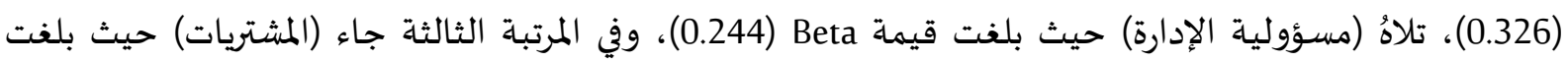

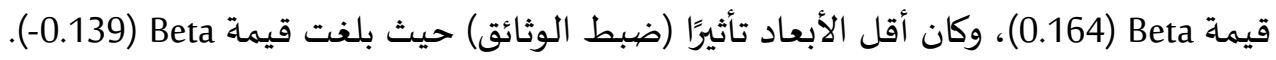

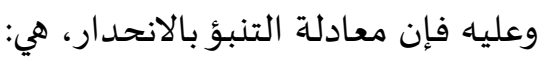
$Y=\alpha+b_{1} x_{1}+b_{2} x_{2}+b_{3} x_{3}+b_{4} x_{4}$

مناقشـة النتائج: مناقشة نتائج الفرضية الأولى: أظهرت نتائج الدراسـة أن هناك أثرا ذا دلالة إحصائية عند مستوى الدلالة

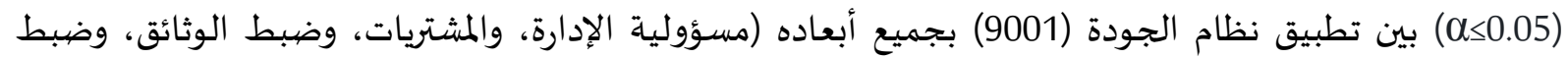
سجلات الجودة) في ضبط الأمور الإدارية في وزارة التربية والتعليم (دراسة تطبيقية تربية التبادة الأغوار الجنوبية).

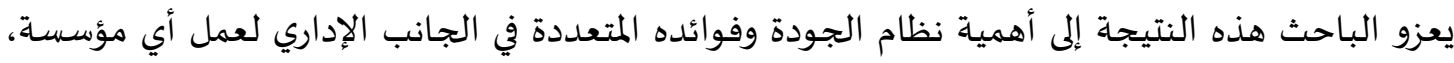

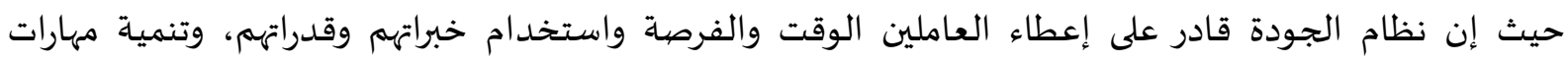
العاملين من خلال المشاركة في تطوير أساليب وإجراءات العمل، وتوفير التدريب اللازم، ومساعدة المؤسسة على على إنى

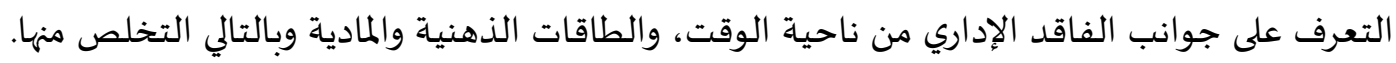

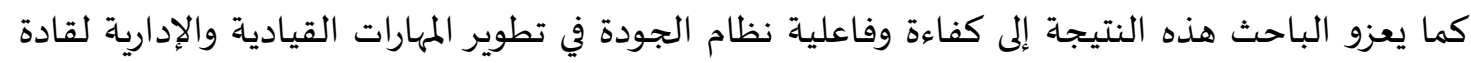

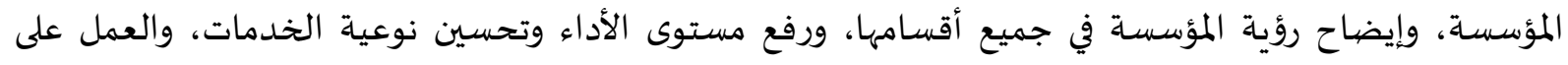

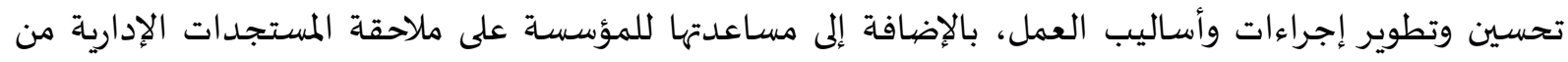

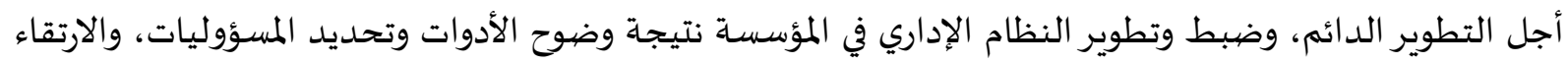
بمستوى العاملين في جميع الجوانب الجسمية والعقلية والاجتماعية والنفسية والروحية النية. 
وتتفق هذه النتيجة مع دراسة (السعيدية، 2017) التي توصلت إلى أن هناك أثر لدرجة تطبيق نظام إدارة

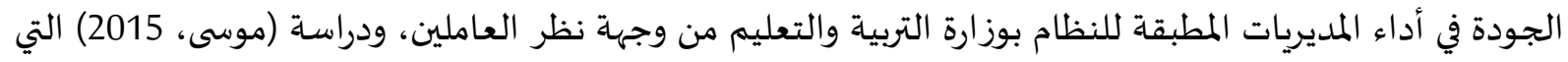
توصلت إلى وجود علاقة ذات دلالة إحصائية بين تطبيق نظم إدارة الجودة وتحسين الأداء المؤسسي بهيئة الجمارك ودئك السودانية.

مناقشة نتائج الفرضية الثانية: أظهرت نتائج الدراسـة أن هناك أثر ذو دلالة إحصائية عند مستوى الدلالة

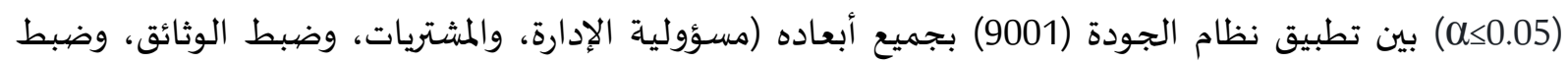
سجلات الجودة) في ضبط الأمور المالية في وزارة التربية والتعليم (دراسة تطبيقية نسية تربية الأغوار الجنوبية).

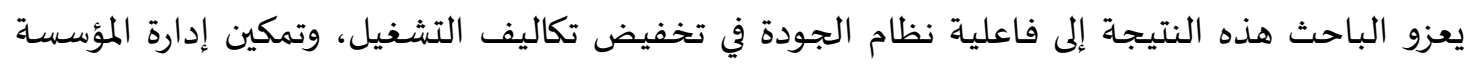

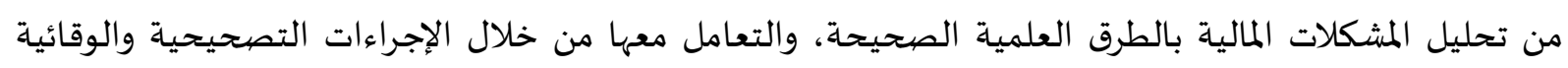

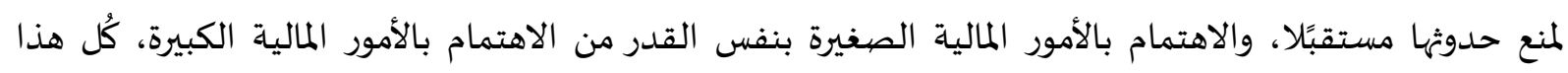
يسهم بشكل كبير بضبط الأمور المالية في المؤسسة. كما يعزو الباحث هذه النتيجة إلى أن تطبيق نظام الجودة يساعد المؤسسة على تلمدئ تحديد احتياجاتها من

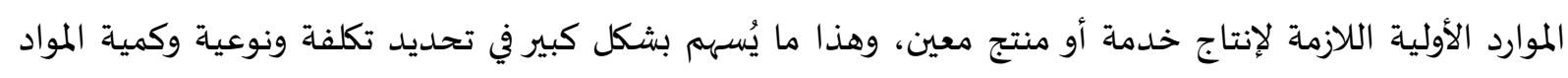

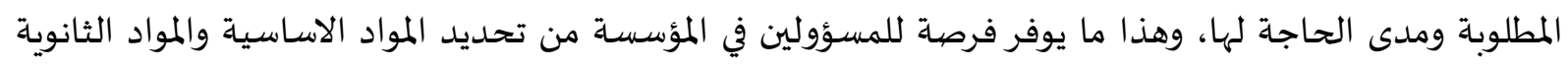

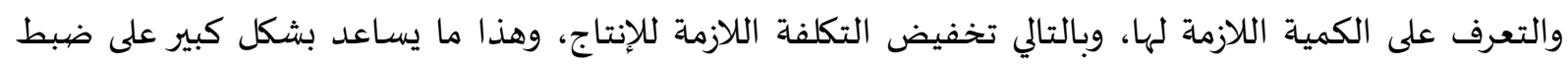

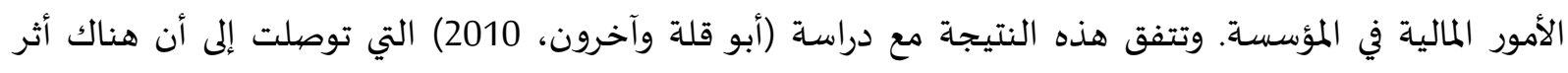

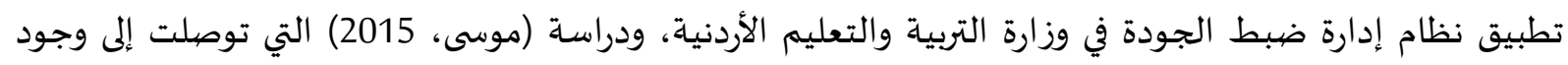

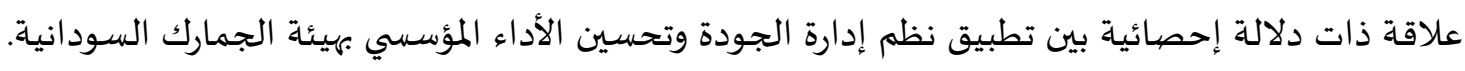

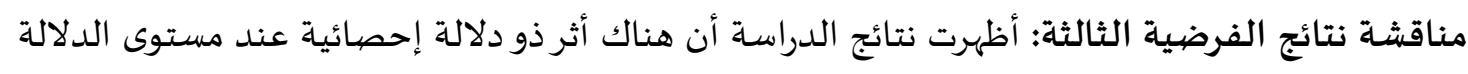

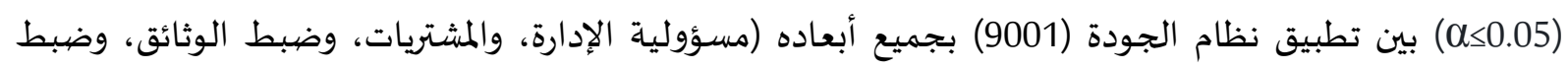

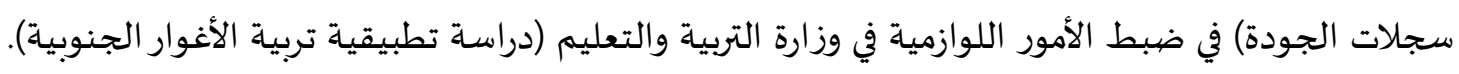
يعزو الباحث هذه النتيجة إلى كفاءة وفاعلية نظام الجودة في تنظيم المواد واللوازم التي تستخدمادها المؤسسة في العملية الانتاجية، حيث أن نظام الجودة يوفر معلومات كافية للمسؤولين في المؤسسة حول كمية المية المواد المواد

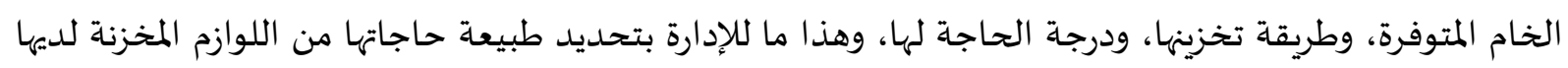

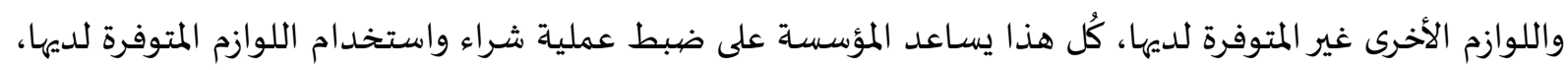
وبالتالي ضبط الأمور اللوازمية. كما يعزو الباحث هذه النتيجة إلى أن نظام الجودة يوفر تقارير متكاملة لإدارة المؤسسة حول مخزونها

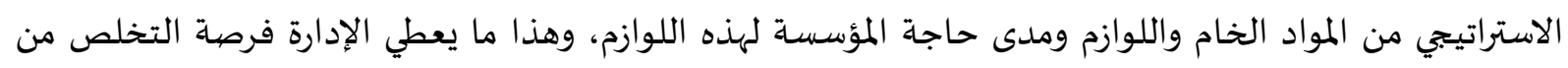

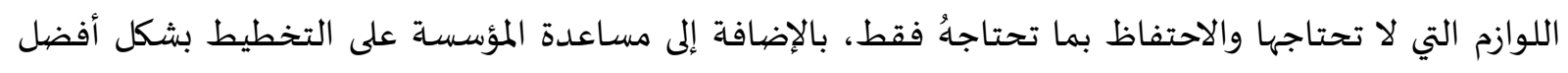

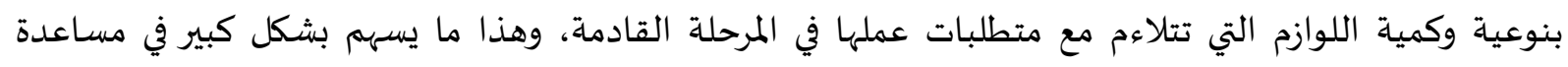

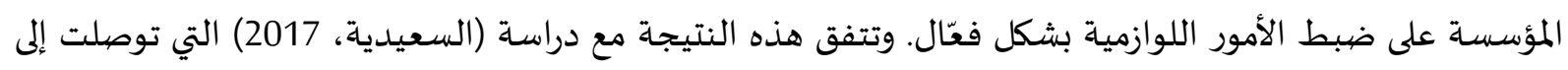

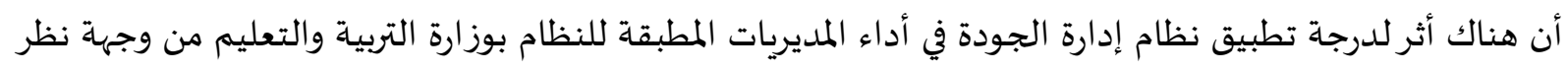

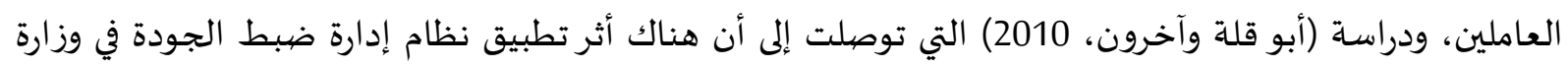
التربية والتعليم الأردنية. 


$$
\text { في ضوء ما تم التوصل إليه من نتائج، يوصي البحث بمات يلي: }
$$

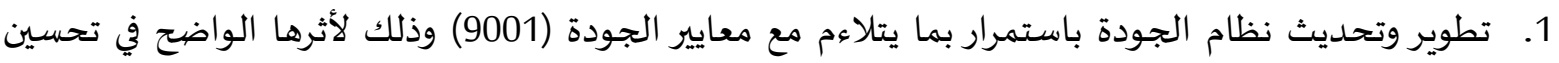

أداء مديرية التربية والتعليم في الأغوار الجنوبية والعاملين فيها.

2. العمل على تجسيد معايير ومبادئ نظام الجودة (9001) في الثقافة التنظيمية لمديرية تربية وتعليم الأغوار الجنوبية، بحيث تصبح سمة رئيسية لمحور الثقافة التنظيمية وركيزة أساسية لإنجاح أدائها وتحقيق أهدافياه ترديا. 3. إنشاء مركز للجودة داخل مديرية تربية وتعليم الأغوار الجنوبية للتأكد من تطبيق نظام الجودة بشكل فئل فعّال وصحيح، ومتابعة تطبيق معاييره في جميع أقسام المديرية.

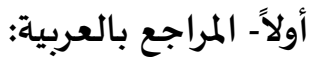

- أبو قلة، محمد، والسكارنه، بلال، وعبد القادر، محمد، والزرقان، صالح (2010). أثر تطبيق نظام إدارة الجودة

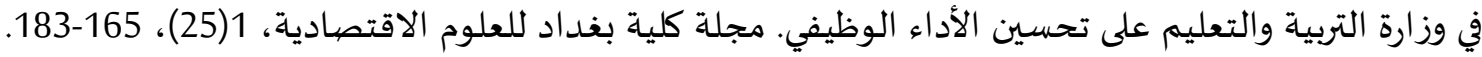
بدح، أحمد وحوامدة، باسم (2013). درجة تطبيق عناصر مواصفات المنظمة الدولية للمقاييس ( ISO 9001:2000) في المدارس الأردنية الحكومية المطبقة فيها. دراسات العلوم التربوية، 40(3)، 887-9032. بكر، هديل (2018). نماذج ضمان الجودة والاعتماد المدرسي والمؤسسي والبرامج الاكاديمياة، الاعتماد كمؤشر

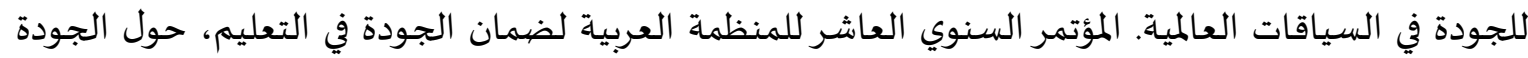
والاعتماد في التعليم، 2-3 كانون الأول، عمّان. - الحلو، هشام؛ وتعرابت، عبد اللطيف (2020). معيقات تطبيق إدارة الجودة الشاملة في مؤسسات التربية

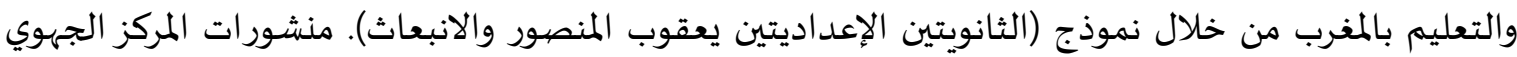
لمهن التربية والتكوين لجهاة طنجة تطوان الحسيمة، المغرب.

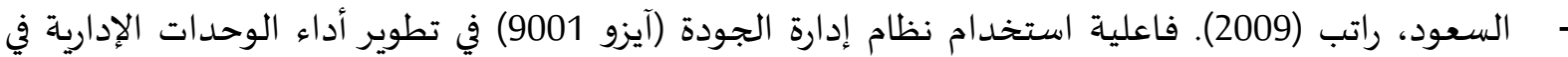
وزارة التربية والتعليم في الأردن من وجها نظر العاملين فهها ودرجة رضاهم عن هذا النظام. مجلة عجمان للدراسات والبحوث، 8(1)، السعيدية، رقية (2017). درجة تطبيق نظام إدارة الجودة في أداء المديريات العامة المطبقة للنظام بوزارة التربية

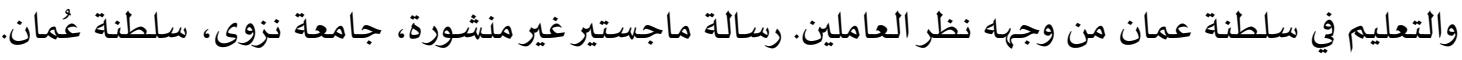

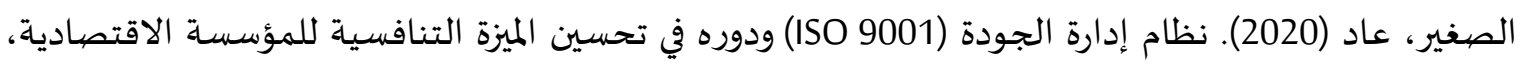

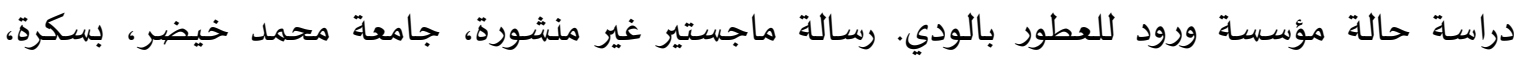
الجزائر. صقر، علي (2013). درجة تطبيق معايير إدارة الجودة الشاملة في تعليم وتدريب طلبة مركز إعداد رجال الإطفاء

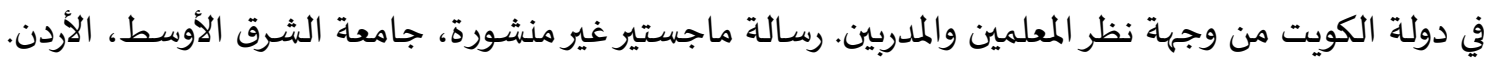

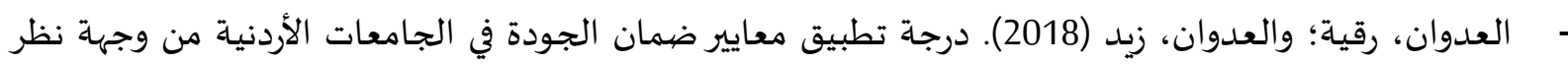

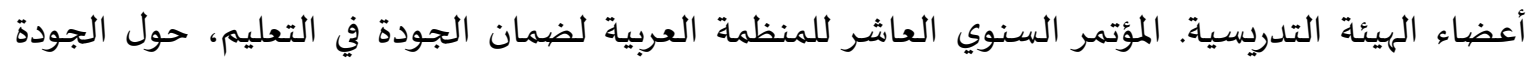
والاعتماد في التعليم، 2-3 كانون الأول، عمّان. 
محافظة، سامح؛ وفريحات، حنان (2011). درجة ممارسة إدارة الجودة الشـاملة في مديريات تربية محافظة الزرقاء من وجهة نظر مديري التربية والتعليم ورؤساء الأقسام. دراسات العلوم التربوية، 38(7)، 2366-2387. موسى، فيصل (2015). أثر تطبيق نظم إدارة الجودة (ISO 9001/2008) على تحسين الأداء المؤسسي بالمؤسسات الخدمية (2014-2010م) هيئة الجمارك السودانياة. أطروحة دكتوراه غير منشورة، جامعة السودان للعلوم والتكنولوجيا، السودان.

\section{ثانياً- المراجع بالإنجليزية:}

- Besterfield, D. (2003). Total Quality Management. (3rd Ed.). Pearson Education International, Prentice-Hall.

- Bhuiyan, N\& Alam, N. (2005). An investigation into issues related to the latest version of ISO 9000. Total Quality Management, 16 (2), 199-213.

- Cheung. T. C. and Yipping, W. 2008. The feasibility of implementing total quality management principles in Chinese education: Chinese educators, perspectives. Educational planning, 2 (17): 10-22.

- Kim, D. Y., Kumar, V \& Kumar, U. (2011). A performance realization framework for implementing ISO 9000. International Journal of Quality \& Reliability Management, 28(4), 383-404. 